\title{
Simultaneous Pontine and Basal Forebrain Microinjections of Carbachol Suppress REM Sleep
}

\author{
Helen A. Baghdoyan, Jeffrey L. Spotts, and Scott G. Snyder \\ Department of Anesthesia, The Pennsylvania State University, College of Medicine, Hershey, Pennsylvania 17033
}

This study was performed to test the hypothesis that cholinoceptive basal forebrain systems can significantly influence cholinoceptive pontine mechanisms known to be important for generating rapid eye movement (REM) sleep. This hypothesis was examined by microinjecting the cholinergic agonist carbachol or saline (vehicle control) into the pons, the basal forebrain, or simultaneously into the pons and basal forebrain, while quantifying the effects on sleep and wakefulness in unanesthetized, chronically instrumented cats. All microinjections were made during wakefulness and were followed by 2 or $4 \mathrm{hr}$ of recording. Polygraphic records were scored for wakefulness, non-REM sleep, REM sleep, and the REM sleep-like state evoked by pontine administration of carbachol (DCarb). Dependent variables quantified following each microinjection included the percentage of recording time spent in each state, the latency to onset of non-REM, REM, and DCarb, the number of episodes per hour of each state, and the duration of the longest episode of each state.

A total of 149 microinjections were made into 15 forebrain and 11 pontine sites in eight cats. Basal forebrain administration of carbachol significantly increased wakefulness. Pontine microinjection of carbachol produced a state that polygraphically and behaviorally resembled REM sleep. This REM sleep-like state occurred in amounts significantly greater than natural REM sleep. Pontine carbachol also significantly decreased wakefulness and non-REM sleep. Simultaneous injection of carbachol into the pons and basal forebrain enhanced REM sleep, but the magnitude of this enhancement was significantly less than the increase in REM sleep evoked by carbachol injection into the pons alone.

The results show that cholinoceptive regions of the basal forebrain can increase wakefulness and reduce the ability of pontine carbachol to evoke the REM sleep-like state. These findings suggest that basal forebrain administration of carbachol activates an arousal-generating system that can successfully compete with the powerful cholinergic REM sleepgenerating system of the pons.

\footnotetext{
Received Nov. 25, 1991; revised July 10, 1992; accepted July 16, 1992.

This work was supported by the Department of Anesthesia, the NIMH (Grant MH45361 to H.A.B.), and a Ciba Geigy Young Investigator award (H.A.B.). We thank Dr. Julien F. Biebuyck for departmental support, Zuzana Lorinc for skillful computer programming, Retsuko Spayde and Mary Ann Royles for excellent secretarial assistance, and Thomas K. Dickinson and William C. Gamberino for help with data collection.

Correspondence should be addressed to Helen A. Baghdoyan, Ph.D., at the above address.

Copyright (C) 1993 Society for Neuroscience $0270-6474 / 93 / 130229-14 \$ 05.00 / 0$
}

[Key words: REM sleep, medial pontine reticular formation, basal forebrain, carbachol, pedunculopontine tegmental nucleus, laterdorsal tegmental nucleus, caudate nucleus]

Pontine cholinergic and cholinoceptive mechanisms play a key role in the generation of rapid eye movement (REM) sleep (reviewed in Chase and Morales, 1990; Hobson, 1990; Steriade and McCarley, 1990; Jones, 1991; Lydic and Baghdoyan, 1993). The concept of cholinergic REM sleep generation has been supported by the finding that microinjection of cholinergic agonists and $\mathrm{AChE}$ inhibitors into the medial pontine reticular formation (mPRF) reliably produces a REM sleep-like state. The evocation of the REM sleep-like state has been shown to depend upon the site of drug administration within the pons (Baghdoyan et al., 1987; Vanni-Mercier et al., 1989; Yamamoto et al., 1990), to be dose dependent (Baghdoyan et al., 1984a, 1989), and to be blocked by specific muscarinic receptor antagonists (Baghdoyan et al., 1989; Lydic et al., 1989; Velazquez-Moctezuma et al., 1991). To date, the cholinoceptively evoked REM sleep-like state provides the only phenomenologically adequate model of REM sleep (Greene et al., 1989).

Although neurons of the MPRF are cholinoceptive (i.e., they possess cholinergic receptors), they are not cholinergic, since they do not contain ChAT (Jones and Beaudel, 1987; Vincent and Reiner, 1987). The cholinergic input to the mPRF arises from the laterodorsal tegmental (LDT) and pedunculopontine tegmental (PPT) nuclei of the dorsolateral pons (Mitani et al., 1988; Shiromani et al., 1988). Several lines of evidence suggest that the cholinergic projections from these nuclei to the mPRF are functionally important. Electrical stimulation of the PPT causes increased $\mathrm{ACh}$ release in the mPRF (Lydic and Baghdoyan, 1992). Lesions of the pontine cholinergic nuclei disrupt REM sleep (Webster and Jones, 1988; Shouse and Siegel, 1992), and extracellular recordings of dorsolateral pontine neurons in chronically implanted cats (El Mansari et al., 1989; Steriade et al., 1990) and rats (Kayama et al., 1992) have revealed populations of putatively cholinergic neurons that discharge in relation to REM sleep. Taken together, these data strongly support the view that cholinergic neurons of dorsolateral pons and noncholinergic, cholinoceptive mPRF neurons are important for REM sleep generation.

The forebrain also has been suggested to play an important role in regulating sleep and wakefulness (reviewed in Mancia and Marini, 1990). It has been pointed out, however, that the idea of forebrain hypnogenic mechanisms still awaits conclusive data at the cellular level (Steriade and McCarley, 1990). In spite of this important limitation, there are several lines of evidence suggesting that the basal forebrain is involved in regulating sleep. 
One of the carliest ideas that the forebrain plays an important role in controlling sleep came from neuropathologic studies correlating lesions of the anterior hypothalamus with insomnia, and lesions of the posterior hypothalamus with hypersomnalence (von Economo, 1929, 1930). These clinical findings were subsequently supported by basic studies showing that insomnia could be produced by experimentally placed lesions of the preoptic basal forebrain (Nauta, 1946) and by ibotenic acidinduced lesions of the mediobasal preoptic area (Sallanon et al., 1989). In intact animals, a small group of neurons that selectively increase their discharge rates prior to and during nonREM sleep have been recorded in the ventral basal forebrain (Szymusiak and McGinty, 1986, 1989).

If the basal forebrain is involved in controlling sleep, it must interact with brainstem cholinergic neurons that are important for REM sleep regulation and for EEG activation during wakefulncss (Stcriadc and Buzsaki, 1990; Steriade et al., 1990). Such an interaction is suggested by both structural and functional evidence. Descending projections from the basal forebrain to the PPT have been described in rat (Swanson et al., 1984, 1987), cat, and monkey (Parent et al., 1988). Electrical stimulation of the rat basal forebrain, including the substantia innominata and lateral preoptic area, can alter the discharge of PPT neurons (Swanson et al., 1984).

In view of the data suggesting an interaction between the basal forebrain and pontine cholinergic neurons involved in REM sleep generation, the present study examined the hypothesis that basal forebrain microinjection of carbachol would significantly alter the ability of mPRF carbachol microinjection to evoke a REM sleep-like state. This hypothesis was tested by microinjecting the cholinergic agonist carbachol into the MPRF, the basal forebrain, or simultaneously into both the MPRF and the basal forebrain while quantifying the effects on sleep and wakefulness.

Portions of these data have been presented previously in abstract form (Baghdoyan, 1991; Baghdoyan et al., 1990).

\section{Materials and Methods}

Animals and stereotaxic aim points. Eight adult male cats were anesthetized with halothane $\left(1.5-3 \%\right.$ in $\left.\mathrm{O}_{2}\right)$ and implanted with recording electrodes to measure states of sleep and wakefulness objectively (Ursin and Sterman, 1981) and with stainless steel guide tubes to permit intracranial drug administration. The electrodes were positioned to record the electroencephalogram (EEG), electrooculogram (EOG), electromyogram (EMG), and ponto-geniculo-occipital (PGO) waves from the lateral geniculate bodies. Two pairs of bilateral guide tubes were implanted in each animal: one pair was aimed for the medial pontine reticular formation (mPRF), known also as the gigantocellular tegmental field (Berman, 1968), and one pair was aimed for various forebrain sites (Berman and Jones, 1982). As previously described, the tips of the guide tubes were left $5 \mathrm{~mm}$ above the targets to minimize cellular damage at the injection sites (Baghdoyan et al., 1987). Cats were given 2-3 weeks to recover from surgery, during which time they were adapted to sleeping in the laboratory.

Pontine aim sites were chosen based upon our previous mapping studies defining a region in the MPRF from which the REM sleep-like state was croked with a short latency and high percentage (Baghdoyan et al., 1984b, 1987). The present study targeted that pontine region by aiming the pontine guide tubes for posterior $(\mathrm{P}) 2.0$ to $\mathrm{P} 3.0$, lateral $(\mathrm{L})$ 1.0 to $\mathrm{L} 1.5$, and vertical (V) -6.0 (coordinates according to the sagittal plates in Berman, 1968). The present study is the first to assess the potential influence of cholinoceptive basal forebrain sites on the cholinergically induced REM sleep-like state. Thus, in order to test for anatomical specificity and to find the most effective basal forebrain sites, this study began to map the forebrain by aiming guide tubes at sites ranging from anterior (A) 14.5 to A16.0, L1.0 to L5.0, and V4.0 to $\mathrm{V}-1.5$ (coordinates according to the coronal plates in Berman and Jones, 1982).
Intracranial drug administration and experimental design. The microinjection procedure has been previously described in detail (Baghdoyan et al., 1987). Briefly, drug injections were always made during wakefulness, and the cats were head restrained for the 3-5 min necessary for drug administration. During separate experiments, cats received unilateral microinjections of carbachol ( $4 \mu \mathrm{g}$ in $0.25 \mu \mathrm{l}$ of sterile saline) into the pons alone, the forebrain alone, or simultaneously into the pons and the forebrain. Simultaneous pontine and forebrain microinjections were made on the same side of the brain, and each site received $4 \mu \mathrm{g}$ of carbachol. Control injections of saline $(0.25 \mu \mathrm{l})$ were made into every site that received carbachol in all cats. A maximum of three carbachol and three saline injections were made into the same site in the same cat.

Polygraphic recording and scoring of behavioral states. Upon completion of the microinjection procedure, cats were released from head restraint and placed in the recording chamber, where they were free to move. Polygraphic variables were recorded continuously through a shielded cable for 2 or $4 \mathrm{hr}$ beginning at the time of injection onset, and behavior was observed on a video monitor. States of wakefulness (W), non-REM or synchronized (S) sleep, and rapid eye movement (REM) or desynchronized (D) sleep were scored in real time according to standard polygraphic and behavioral criteria (Ursin and Sterman, 1981). The REM sleep-like state produced by pontine microinjection of carbachol (DCarb) was scored according to previously described criteria (Baghdoyan et al., 1984a, 1987). All states were scored in 30 sec epochs, yielding a total of 240 or 480 bins following each microinjection trial.

Data analysis. The polygraphic and behavioral measures provided the following dependent variables quantified for each microinjection trial: (1) percentage of total recording time spent in W, S, and D or DCarb; (2) latency to onset of the first episode of S and D or DCarb, as measured from the time of injection onset; (3) number of episodes of W, S, and D or DCarb per hour; and (4) duration of the longest episode of W, S, and D or DCarb. Analyses of variance and $t$ tests were used to examine the effects of microinjection site (pons vs basal forebrain vs pons and basal forebrain) and drug (carbachol vs saline) on state of consciousness (W, S, D, and DCarb).

Histological localization of injection sites. At the conclusion of the microinjection experiments, cats were deeply anesthetized with pentobarbital $(40 \mathrm{mg} / \mathrm{kg})$ and perfused transcardially with heparinized saline followed by $10 \%$ formalin. The brains were removed and postfixed in $10 \%$ formalin. Frozen sagittal brainstem sections and coronal forebrain sections were cut at $40 \mu \mathrm{m}$ in thickness, mounted on chromealum-coated slides, and stained with cresyl violet. All histological sections that contained a lesion made by the microinjector were projected and drawn, and the injection sites were localized according to the sagittal plates in Berman (1968) and the coronal plates in Berman and Jones (1982). Figure 1 shows a representative histological section that includes one injection site in the pons (Fig. $1 A$ ) and one injection site in the basal forebrain (Fig. $1 B$ ).

\section{Results}

A total of 149 microinjections were made into 15 forebrain and 11 pontine sites. The effects of pontine carbachol on behavioral state are known to depend upon the site of carbachol administration within the pons (Baghdoyan et al., 1987; Vanni-Mercier et al., 1989; Yamamoto et al., 1990). Therefore, the analyses reported below quantify the effects on D sleep of microinjecting carbachol into the pons (Table 1 ). In addition, the present results describe for the first time the effects of pontine carbachol administration on the latency, frequency, and duration of $W$ and $S$ sleep (Table 1). The results are organized into nine subsections: (1) histological analyses, (2) timing of sleep and wakefulness, (3) effects of basal forebrain carbachol on percentage of state, (4) effects of basal forebrain carbachol on sleep latency, (5) effects of basal forebrain carbachol on the frequency of behavioral state episodes, (6) effects of basal forebrain carbachol on the duration of behavioral state episodes, (7) state-independent polygraphic sleep signs, (8) behaviors during wakefulness, and (9) effects of carbachol injections into the caudate nuclcus.

Histological analyses. Figure $2 A$ shows the location of all pontine injection sites. As summarized in Table 1 , microinjec- 


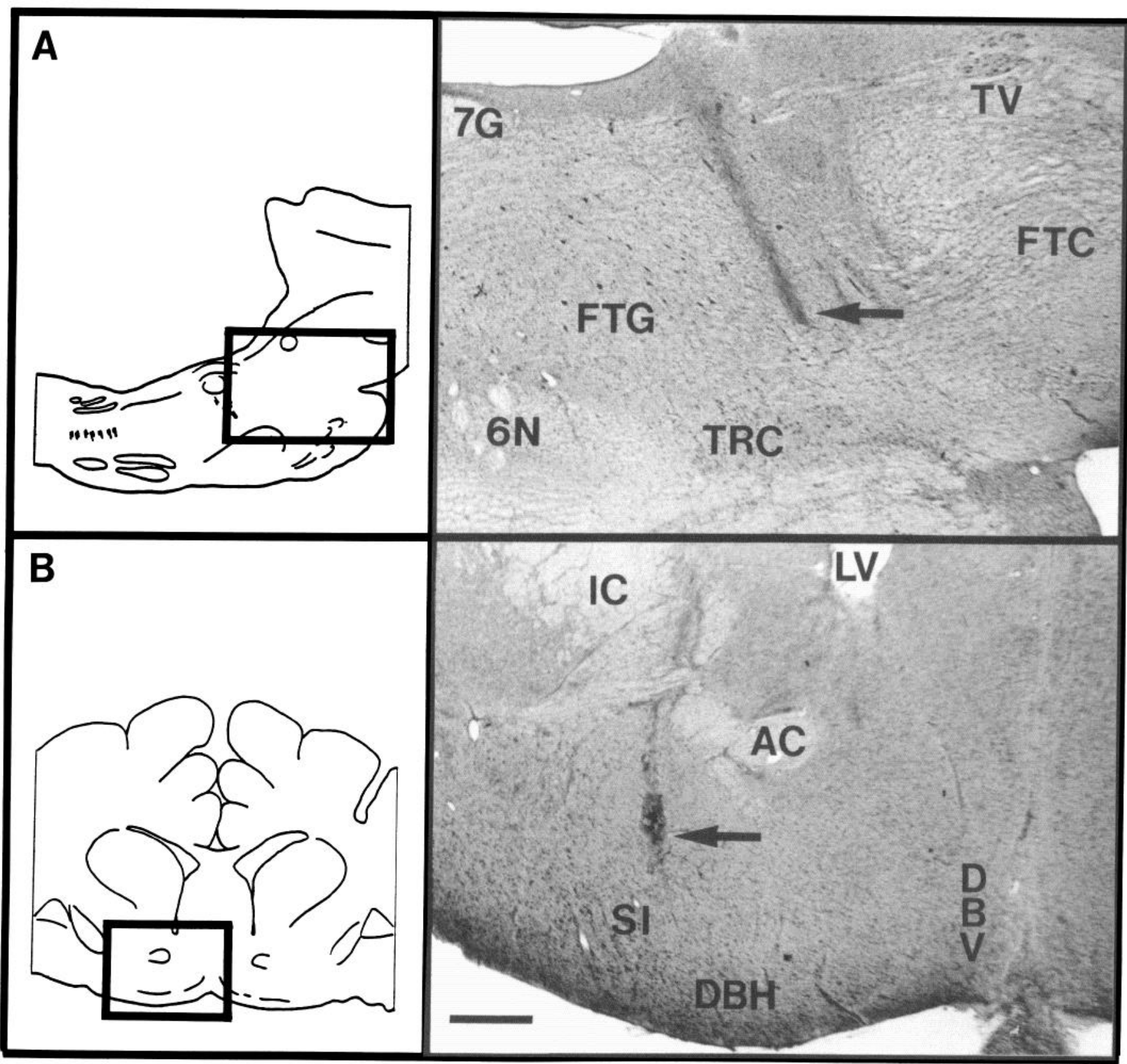

Figure 1. Histological localization of injection sites. A, Line drawing of a sagittal section of the cat brainstem at $1.2 \mathrm{~mm}$ from the midline (modified from Berman, 1968). Rostral is to the right. The boxed area is enlarged in the adjacent photomicrograph. The arrow on the photomicrograph marks the tip of the injection site, located in the mPRF (also called gigantocellular tegmental field). $6 N$, abducens nerve; $7 G$, genu of the facial nerve; $F T C$, central tegmental field; $F T G$, gigantocellular tegmental field; $T R C$, tegmental reticular nucleus, central division; $T V$, ventral tegmental nucleus. $B$, Line drawing of a coronal section of the cat forebrain at $15.6 \mathrm{~mm}$ anterior to stereotaxic zero (modified from Berman and Jones, 1982). The boxed area is enlarged in the adjacent photomicrograph. The arrow on the photomicrograph marks the tip of the injection site, located in the substantia innominata $(S I)$. $A C$, anterior commissure; $D B H$, nucleus of the diagonal band of Broca, horizontal division; $D B V$, nucleus of the diagonal band of Broca, vertical division; $I C$, internal capsule; $L V$, lateral ventricle. Scale bar, $1 \mathrm{~mm}$ for both photomicrographs.

tion of carbachol into these sites significantly increased the percentage, frequency, and duration of DCarb and significantly reduced the latency to onset of DCarb. Table 1 also shows that, with the exception of $\mathrm{W}$ frequency, all dependent measures of $\mathrm{W}$ and $\mathrm{S}$ sleep were significantly decreased by pontine carbachol administration.

Figure $2 B$ shows the location of all forebrain injection sites. Forebrain injections were made into the caudate nucleus and the basal forebrain, including the substantia innominata and the diagonal band of Broca. For subsequent statistical analyses of the mean effects on state of forebrain carbachol, the data were divided into two groups based upon location of the forebrain injection site. Data obtained following microinjection into the basal forebrain (Fig. $2 B$, circles; $N=11$ sites in 6 cats) were averaged together and the results of these analyses are summarized in Figures 4-8 and Tables 2 and 3. Statistical analyses were not performed on data obtained following microinjections into the caudate nucleus (Fig. $2 B$, triangles; $N=4$ sites in 2 cats).

Timing of sleep and wakefulness. Figure 3 illustrates a series 


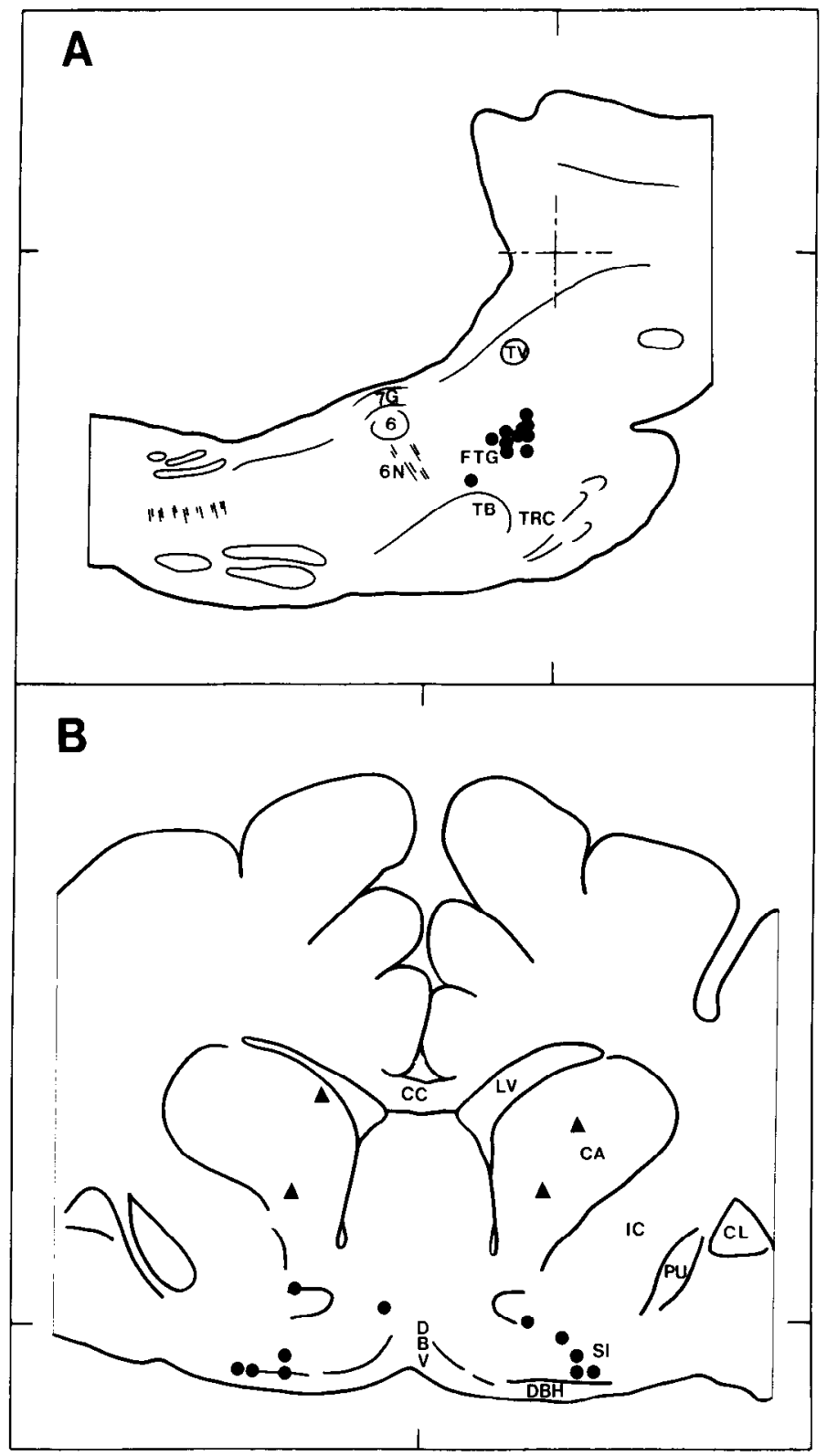

Figure 2. Localization of all pontine and forebrain injection sites. $A$, Circles locate the 11 pontine injection sites on a sagittal schematic drawing of the cat brainstem at Ll.2 (modified from Berman, 1968). The mean $( \pm \mathrm{SD})$ lateral coordinate of all pontine sites was $\mathrm{L} 1.2 \pm 0.4$. Tick marks on the box surrounding the schematic indicate stereotaxic zero in the anterior-posterior and dorsal-ventral planes. 6 , abducens nucleus; $6 N$, abducens nerve; $7 G$, genu of the facial nerve; $F T G$, gigantocellular tegmental field; $T B$, trapezoid body; $T R C$, tegmental reticular nucleus, central division; $T V$, ventral tegmental nucleus. $B$, The 11 basal forebrain (circles) and four caudate nucleus (triangles) injection sites are indicated on a coronal, schematic drawing of the cat forebrain at A15.6 (modified from Berman and Jones, 1982). The mean ( \pm SD) anterior coordinate of all forebrain sites was A15.2 \pm 0.7 . Tick marks on the box surrounding the schematic indicate stereotaxic zero in the mediallateral and dorsal-ventral planes. $C A$, caudate nucleus; $C C$, corpus callosum; $C L$, claustrum; $D B H$, nucleus of the diagonal band of Broca, horizontal division; $D B V$, nucleus of the diagonal band of Broca, vertical division; $I C$, internal capsule; $L V$, lateral ventricle; $P U$, putamen; $S I$, substantia innominata.

of experiments in one animal, showing the effects on sleep and wakefulness of microinjecting carbachol into the pons alone (Fig. 3, top left), the forebrain alone (Fig. 3, middle left), and simultaneously into the pons and the forebrain (Fig. 3, bottom
Table 1. Effects of pontine carbachol on sleep and wakefulness

\begin{tabular}{lccc} 
& Saline & Carbachol & $p$ \\
\hline Wakefulness & & & \\
Percentage & $61.1+20.3$ & $43.9 \pm 16.2$ & 0.008 \\
Frequency & $5.5 \pm 2.3$ & $5.4 \pm 3.1$ & 0.892 \\
Duration & $48.1 \pm 34.0$ & $25.7 \pm 17.5$ & 0.018 \\
S sleep & & & \\
Percentage & $33.6 \pm 16.7$ & $0.4 \pm 0.9$ & 0.00 \\
Latency & $42.6 \pm 37.0$ & $207.4 \pm 76.8$ & 0.00 \\
Frequency & $5.4 \pm 2.2$ & $0.1 \pm 0.2$ & 0.00 \\
Duration & $14.8 \pm 9.1$ & $0.5 \pm 1.4$ & 0.00 \\
D sleep or DCarb & & & \\
Percentage & $5.3 \pm 6.4$ & $55.8 \pm 16.4$ & 0.00 \\
Latency & $161.4 \pm 77.2$ & $11.0 \pm 5.9$ & 0.00 \\
Frequency & $0.7 \pm 0.7$ & $5.1 \pm 3.1$ & 0.00 \\
Duration & $5.5 \pm 5.1$ & $37.6 \pm 16.3$ & 0.00
\end{tabular}

Data are mean $( \pm \mathrm{SD})$ effects on state of microinjecting saline $(0.25 \mu \mathrm{l} ; N=18$ trials into 10 sites in 7 cats) or carbachol $(4.0 \mu \mathrm{g} / 0.25 \mu \mathrm{l} ; N=18$ trials into 10 sites in 6 cats) into the mPRF. All injections were performed during wakefulness. Dependent measures include the percentage of total recording time spent in each state (Percentage), the latency in minutes to onset of the first episode (Latency), the number of episodes per hour (Frequency), and the duration in minutes of the longest episode per trial (Duration). Significance levels are given in the last column $(p)$

left). As previously reported (Table 1; Baghdoyan et al., 1984b, 1987, 1989), following pontine carbachol (Fig. 3, top left), S sleep was eliminated and the cat spent much more time in DCarb than it typically spent in D sleep during control recordings (Fig. 3, top right). Forebrain carbachol (Fig. 3, middle left) produced a marked suppression of both $S$ sleep and D sleep, with a concomitant increase in wakefulness (compare Fig. 3, middle left and middle right). The effects of simultaneous pontine and forebrain carbachol administration (Fig. 3, bottom left) were to produce wakefulness during the first hour postinjection and DCarb during 2-4 hr postinjection, and to eliminate $S$ sleep for the entire $4 \mathrm{hr}$ recording period.

Visual inspection of Figure 3 shows that in addition to altering the amount of time spent in W, S sleep, and D sleep, carbachol also had site-specific effects on the latency, frequency, and duration of sleep and wakefulness. The next four sections describe, in a quantitative manner, the mean effects on behavioral state of carbachol administration. These data show that basal forebrain administration of carbachol exerted significant effects on the percentage, latency, and frequency of behavioral states. In general, the effects of basal forebrain carbachol on $\mathrm{W}$ and on $\mathrm{D}$ sleep were opposite in direction to the effects on behavioral state produced by pontine administration of carbachol. Simultaneous pontine and basal forebrain carbachol microinjections also significantly altered all dependent measures of behavioral state. The major finding to emerge from these simultaneous pontine and basal forebrain microinjections is that basal forebrain administration of carbachol diminished the powerful D sleepenhancing effects produced by microinjecting carbachol into the pons. This finding is summarized in Figure 4, which shows that the enhancement of D sleep produced by pontine carbachol administration (solid bars) was reduced following simultaneous administration of carbachol into the pons and basal forebrain (crosshatched bars).

Effects of basal forebrain carbachol on percentage of state. The effects of microinjecting carbachol on the percentage of time 

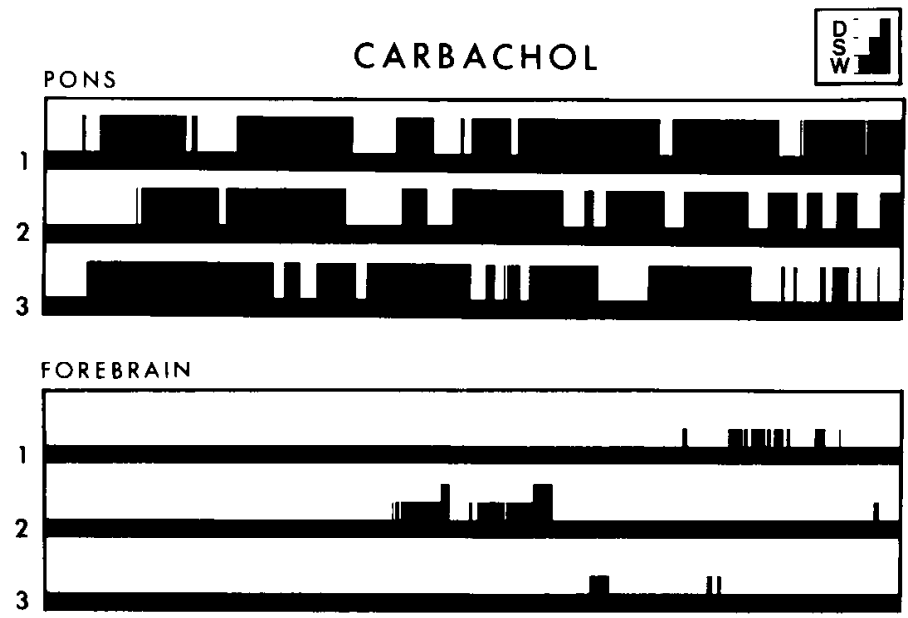

PONS \& FOREBRAIN
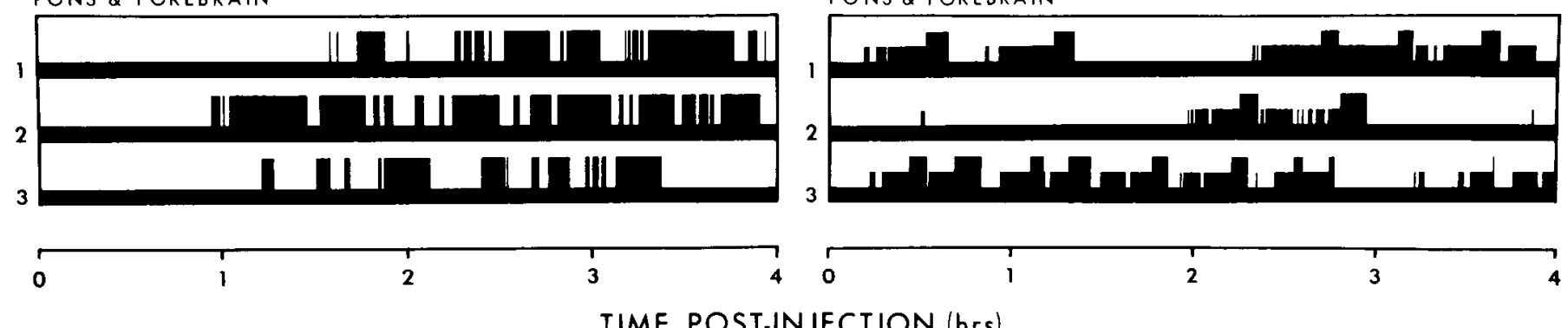

Figure 3. Temporal distribution of sleep and wakefulness. These histograms plot the occurrence and duration of polygraphically and behaviorally defined W, S sleep, D sleep, and DCarb for a series of experiments in one cat. Three microinjection trials (labeled $1-3$ ) were performed for each condition, for a total of 18 trials in this animal. The two small boxes at the top labeled $W, S$, and $D$ indicate that the short solid bars represent $W$, the medium-height solid bars represent S sleep, and the tall solid bars represent D sleep or DCarb. Microinjections of carbachol (left) or saline $(r i g h t)$ were made into the pons (top), the forebrain (middle), and simultaneously into the pons and forebrain (bottom). Microinjections were made at time $=0 \mathrm{hr}$. For this animal, all injections were followed by $4 \mathrm{hr}$ of recording.

spent in W, S sleep, D sleep, and DCarb are summarized in Figure 5. ANOVA revealed significant site and drug main effects on all threc states (see Fig. 5 caption for $F$ values and probability levels).

The effects on wakefulness of pontine carbachol administration are shown in the left histograms of Figure $5 \mathrm{~A}$ and are described in detail in Table 1. The middle histograms of Figure $5 A$ show that microinjection of carbachol into the basal forebrain caused a significant increase in wakefulness compared to saline-injected controls $(t-2.17 ; \mathrm{df}-50 ; p=0.035)$. The solid histograms of Figure $5 \mathrm{~A}$ compare the percentage of total recording time spent in wakefulness following carbachol injection into the pons, the basal forebrain, and simultaneously into the pons and basal forebrain. ANOVA revealed a significant site main effect of carbachol on the percentage of time spent in wakefulness $(F=6.417 ; \mathrm{df}=2,46 ; p=0.003)$. Injection site comparisons showed a significant reduction in wakefulness following pontine carbachol compared to wakefulness following basal forebrain carbachol alone (Fig. $5 \mathrm{~A}$, solid histograms, left vs middle; $t=3.34 ; \mathrm{df}=34 ; p=0.002)$. Similar results were obtained when the percentage of wakefulness following carbachol injection into pontine sites was compared to wakefulness following carbachol administered simultaneously to pontine and basal forebrain microinjection sites (Fig. $5 \mathrm{~A}$, solid histograms, left vs right; $t=3.27 ; \mathrm{df}=21 ; p=0.004)$. Thus, simultaneous microinjection of carbachol into the pons and basal forebrain blocked the ability of pontine carbachol to decrease wakefulness significantly.
Figure $5 B$ shows the percentage of recording time spent in $\mathrm{S}$ sleep following carbachol and saline microinjections into the pons, the basal forebrain, and simultaneously into the pons and basal forebrain. The effects of pontine carbachol on $S$ sleep percentage are shown in the left histograms of Figure $5 B$ and are described in Table 1 . The reduction in $S$ sleep percentage following basal forebrain carbachol administration was not statistically significant (Fig. $5 B$, middle histograms; $t=1.94$; df $=$ $50 ; p=0.058)$. Simultaneous pontine and basal forebrain carbachol administration did significantly reduce $S$ sleep percentage below saline control levels (Fig. $5 B$, right histograms; $t=3.99$; $\mathrm{df}=24 ; p=0.001$ ).

Figure $5 C$ shows the effects on D sleep of microinjecting carbachol into the pons, the basal forebrain, and simultaneously into the pons and basal forebrain. The left histograms show the enhancement of D sleep evoked by pontine administration of carbachol (see also Table 1). In contrast, microinjection of carbachol into the basal forebrain (Fig. $5 C$, middle histograms) produced a $53 \%$ decrease below control levels in the percentage of recording time spent in D sleep $(t=2.81 ; \mathrm{df}=26 ; p=0.009)$. Thus, basal forebrain administration of carbachol suppressed the amount of natural D sleep.

Simultaneous pontine and basal forebrain carbachol administration produced a significant increase in DCarb over control levels of D sleep (Fig. $5 C$, right histograms; $t=4.21$; $\mathrm{df}=24$, $p<0.000$ ). Note, however, that the animals spent significantly less time in DCarb following simultaneous pontine and basal forebrain carbachol injections than they spent in DCarb follow- 

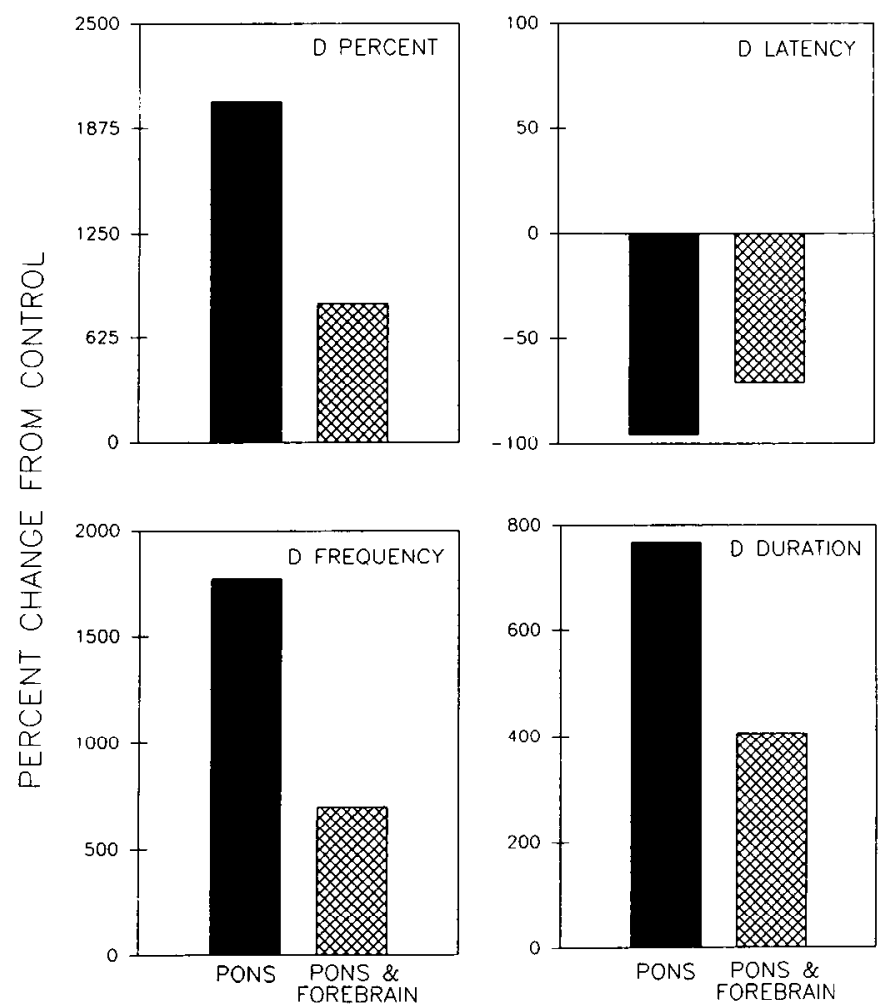

Figure 4. Effect of simultaneous pontine and basal forebrain carbachol administration on pontine-evoked DCarb. These graphs show the percentage change from control for four dependent measures of $\mathrm{D}$ sleep following microinjection of carbachol into the pons (solid bars; $N=10$ trials into 6 sites in 4 cats) and simultaneously into the pons and basal forebrain (crosshatched bars; $N=13$ trials into 6 sites in 4 cats). These histograms represent the percentage increase or decrease from identical measurements that were taken following microinjection of saline into the pons $(N=11$ trials into 7 sites in 5 cats) and simultaneously into the pons and basal forebrain ( $N=13$ trials into 6 sites in 4 cats). For all measures except $D$ latency, the combined pontine and basal forebrain carbachol injections significantly diminished the effects caused by pontine injection of carbachol.

ing only pontine carbachol administration (Fig. $5 C$, solid histograms, right vs left, $24.2 \%$ vs $55.5 \%$ of total recording time, respectively; $t=4.02 ; \mathrm{df}=21 ; p=0.001$ ). Thus, simultaneous pontine and basal forebrain microinjection of carbachol significantly decreased the ability of pontine carbachol to produce a D sleep-like state (see also Fig. 4, top left). While previous studies have shown that pontine cholinoceptive D sleep enhancement can be blocked by direct antagonism of muscarinic, cholinergic receptors (Baghdoyan et al., 1984a, 1989; Lydic et al., 1989; Imeri et al., 1991; Velazquez-Moctezuma et al., 1991), the present results provide the first demonstration that the potent $D$ sleep-enhancing effects evoked by cholinomimetics in the pons can be disrupted by microinjection of a cholinergic agonist into another brain region.

Effects of basal forebrain carbachol on sleep latency. The effects of carbachol administration on behavioral state were also assessed by measuring the latency to onset of the first $\mathbf{S}$ sleep and the first D sleep or DCarb episode. Because all microinjections were made during wakefulness, there was no measure of $\mathrm{W}$ latency. Figure 6 shows the mean latency to onset of S sleep (Fig. 6A) and D sleep or DCarb (Fig. 6B) following microinjection of carbachol or saline into the pons, the basal forebrain, and simultaneously into the pons and basal forebrain. ANOVA
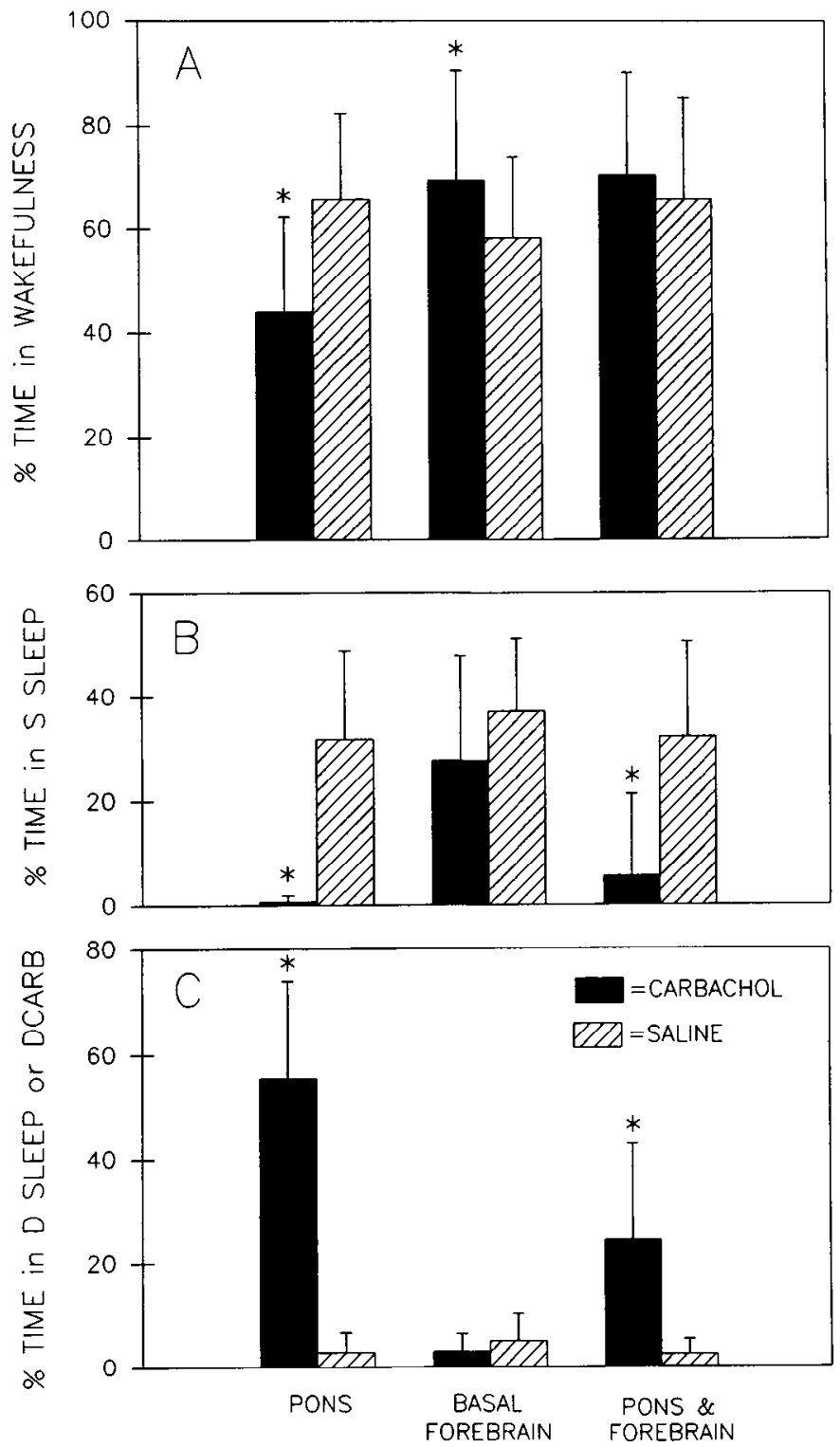

Figure 5. Effects of basal forebrain carbachol on percentage of state. These graphs show the percentage of total recording time spent in $\mathrm{W}$ $(A), \mathrm{S}$ sleep $(B)$, and D sleep or DCarb $(C)$ following microinjection of carbachol (solid bars) or saline (hatched bars) into the pons (carbachol: $N=10$ trials into 6 sites in 4 cats; saline: $N=11$ trials into 7 sites in 5 cats), the basal forebrain (carbachol: $N=26$ trials into 11 sites in 6 cats; saline: $N=26$ trials into 11 sites in 6 cats), and simultaneously into the pons and forebrain (carbachol: $N=13$ trials into 6 sites in 4 cats; saline: $N=13$ trials into 6 sites in 4 cats). Each bar represents the mean and SD. Asterisks indicate that the carbachol value is significantly different $(p<0.05)$ from the control (saline) valuc by $t$ test comparison. See Results for individual $t$ values and probability levels. $A$, Wakefulness. ANOVA revealed no significant drug (carbachol vs saline; $F=$ 0.463 ; df $=1,93 ; p=0.498$ ) or site (pons vs basal forebrain vs pons and forebrain; $F=2.709 ; \mathrm{df}=2,93 ; p=0.072$ ) main effect on the percentage of time spent in W. $B, S$ sleep. ANOVA demonstrated significant site $(F=9.872 ; \mathrm{df}=2,93 ; p<0.000)$ and drug $(F=31.528$; df $=1,93 ; p<0.000$ ) main effects on the percentage of time spent in $\mathrm{S}$ sleep. $C$, D sleep and DCarb. ANOVA showed that there were significant site $(F=50.198 ; \mathrm{df}=2,93 ; p<0.000)$ and drug $(F=69.165$; $\mathrm{df}=1,93 ; p<0.000$ ) main effects on the percentage of total recording time spent in D sleep or DCarb. 

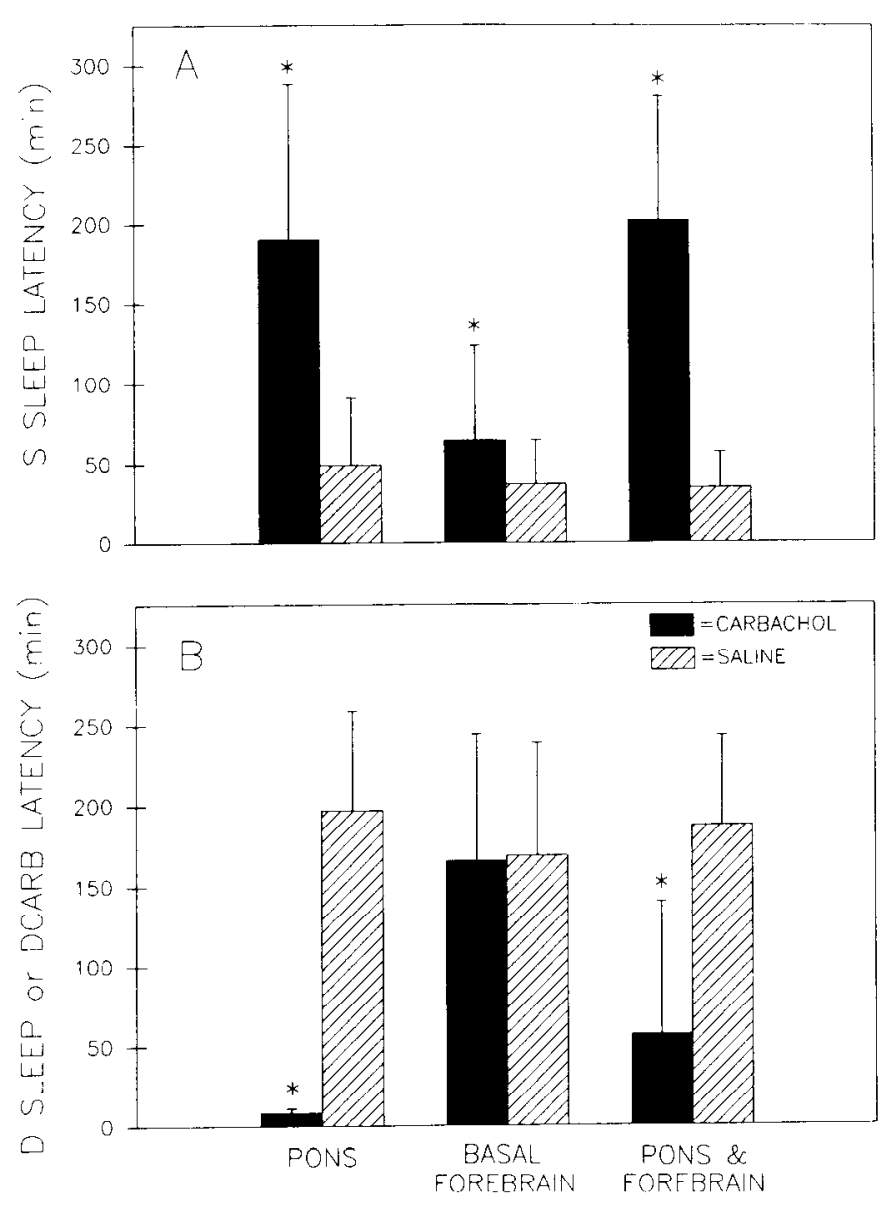

Figure 6. Effects of basal forebrain carbachol on sleep latency. These graphs show the latency to onset of the first $S$ sleep $(A)$ and D sleep or DCarb $(B)$ episode following microinjection of carbachol (solid bars) or saline (hatched bars) into the pons (carbachol: $N=10$ trials into 6 sites in 4 cats; saline: $N=11$ trials into 7 sites in 5 cats), the basal forebrain (carbachol: $N=26$ trials into 11 sites in 6 cats; saline: $N=26$ trials into 11 sites in 6 cats), and simultaneously into the pons and forebrain (carbachol: $N=13$ trials into 6 sites in 4 cats; saline: $N=13$ trials into 6 sites in 4 cats). Each bar represents the mean latency to onset and SD in minutes. Latency was measured from the time of injection onset, and all injections were made during wakefulness. Asterisks indicate that the carbachol value is significantly different $(p<0.05)$ from the control (saline) value by $t$ test comparison. See Results for individual $t$ valucs and probability levels. $A$, S sleep. ANOVA revealed significant site (pons vs basal forebrain vs pons and forebrain; $F=18.434$; $\mathrm{df}=2,93 ; p<$ 0.000 ) and drug (carbachol vs saline; $F=63.852 ; \mathrm{df}=1,93 ; p<0.000$ ) main effects on the latency to onset of the first $\mathrm{S}$ sleep episode. $B, \mathrm{D}$ sleep and DCarb. ANOVA demonstrated significant site $(F=7.625 ; \mathrm{df}$ $=2,93 ; p=0.001)$ and $\mathrm{drug}(F=30.394 ; \mathrm{df}=1,93 ; p<0.000)$ main effects on the latency to onset of the first D sleep or DCarb episode.

revealed significant site and drug main effects on both $S$ sleep and D sleep latency (see Fig. 6 caption for $F$ values and probability levels).

S sleep latency (Fig. 6A) was significantly increased over control values by all carbachol microinjections (solid vs hatched histograms), independent of site (pons: left histograms and Table 1; basal forebrain: middle histograms; $t=2.18$; $\mathrm{df}=50 ; p=$ 0.034 ; pons and basal forebrain: right histograms; $t=7.80$; $\mathrm{df}$ $=24 ; p<0.000$ ). As compared with saline-injected controls, basal forebrain carbachol evoked a $78 \%$ increase in $\mathrm{S}$ sleep latency, and simultaneous pontine and basal forebrain administration of carbachol increased S sleep latency by $494 \%$. These

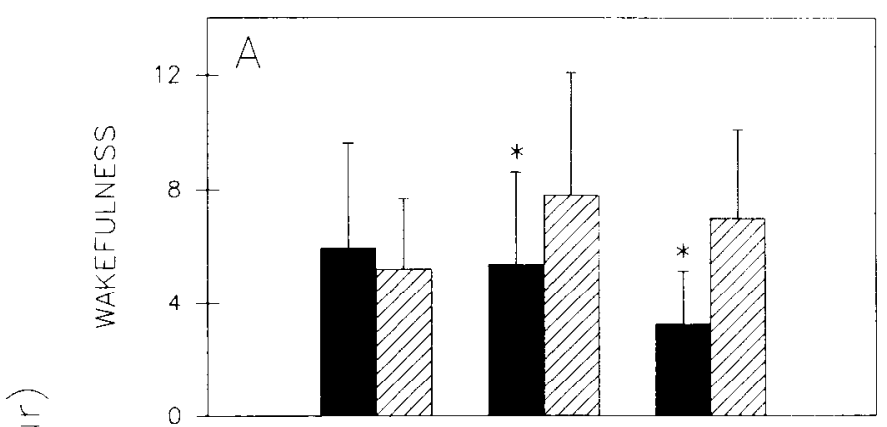

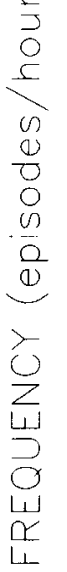
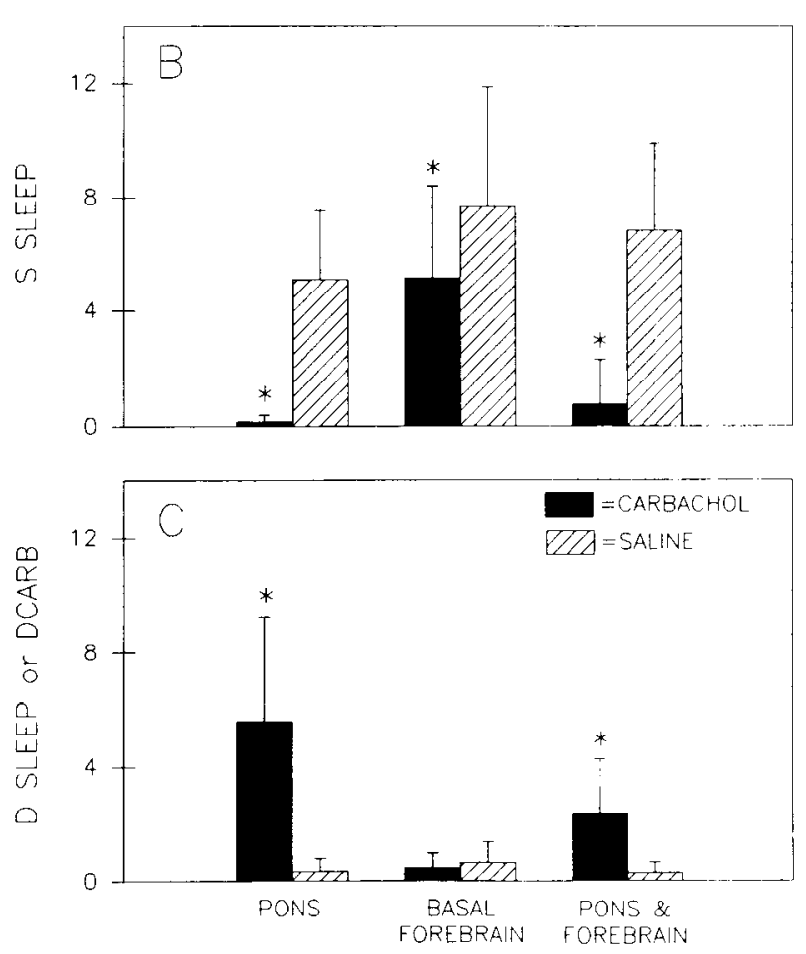

Figure 7. Effects of basal forebrain carbachol on frequency of behavioral state episodes. These graphs show the number of episodes per hour (frequency) of W $(A)$, S sleep $(B)$, and D sleep or DCarb $(C)$ following microinjection of carbachol (solid bars) or saline (hatched bars) into the pons (carbachol: $N=10$ trials into 6 sites in 4 cats; saline: $N=11$ trials into 7 sites in 5 cats), the basal forebrain (carbachol: $N=26$ trials into 11 sites in 6 cats; saline: $N=26$ trials into 11 sites in 6 cats), and simultaneously into the pons and forebrain (carbachol: $N=13$ trials into 6 sites in 4 cats; saline: $N=13$ trials into 6 sites in 4 cats). Each bar represents the mean and SD for the number of episodes per hour of each state. Asterisks indicate that the carbachol value is significantly different $(p<0.05)$ from the control (saline) value by $t$ test comparison. See Results for individual $t$ values and probability levels. $A$, Wakefulness. ANOVA revealed no significant site (pons vs basal forebrain vs pons and forebrain; $F=1.867 ; \mathrm{df}=2,93 ; p=0.160$ ) main effect on W frequency. ANOVA did demonstrate a significant drug (carbachol vs saline; $F=9.526 ; \mathrm{df}=1,93 ; p=0.003$ ) main effect on $\mathrm{W}$ frequency. $B$, S sleep. ANOVA showed significant site $(F=13.234 ; \mathrm{df}=2,93 ; p$ $<0.000)$ and drug $(F=40.144 ; \mathrm{df}=1,93 ; p<0.000)$ main effects on the number of S sleep episodes. $C$, D sleep and DCarb. ANOVA demonstrated significant site $(F=20.437 ; \mathrm{df}=2,93 ; p<0.000)$ and drug $(F=30.051 ; \mathrm{df}=1,93 ; p<0.000)$ main effects on D sleep or DCarb frequency.

findings are consistent with the data of Figure $5 B$, which showed a decrease in S sleep percentage following carbachol injections.

Basal forebrain microinjection of carbachol had no effect on D sleep latency (Fig. $6 B$, middle histograms; $t=0.15 ; \mathrm{df}=50$; $p=0.878$ ). Simultaneous pontine and basal forebrain microin- 


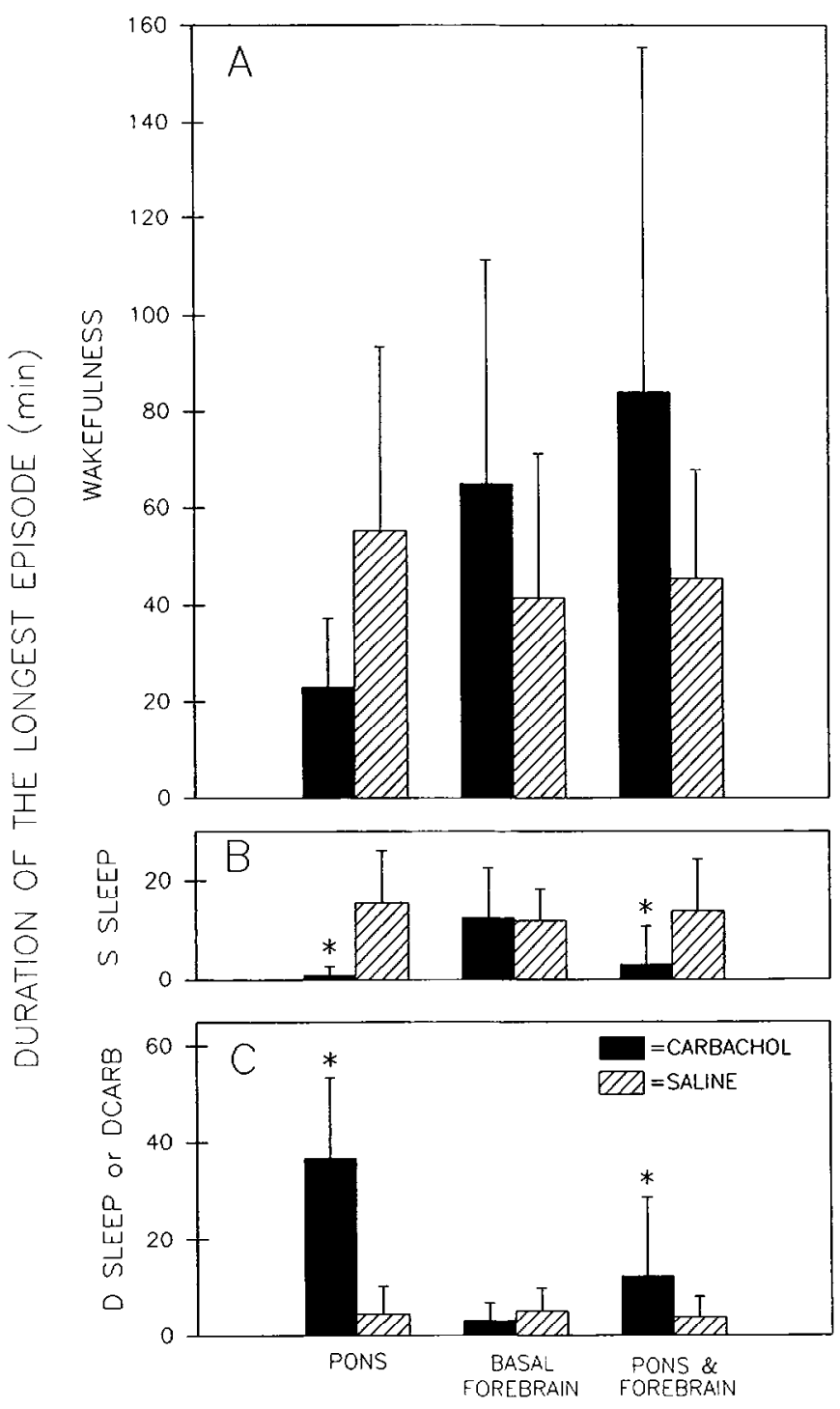

Figure 8. Effects of basal forebrain carbachol on duration of behavioral state episodes. These graphs show the duration of the longest episode per injection trial of W $(A), \mathrm{S}$ sleep $(B)$, and D sleep or DCarb $(C)$ following microinjection of carbachol (solid bars) or saline (hatched bars) into the pons (carbachol: $N=10$ trials into 6 sites in 4 cats; saline: $N$ $=11$ trials into 7 sites in 5 cats), the basal forebrain (carbachol: $N=$ 26 trials into 11 sites in 6 cats; saline: $N=26$ trials into 11 sites in 6 cats), and simultaneously into the pons and forebrain (carbachol: $N-$ 13 trials into 6 sites in 4 cats; saline: $N=13$ trials into 6 sites in 4 cats). Each bar represents the mean duration of the longest episode and SD in minutes. Asterisks indicate that the carbachol value is significantly different $(p<0.05)$ from the control (saline) value by $t$ test comparison. See Results for individual $t$ values and probability levels. $A$, Wakefulness. ANOVA revealed no significant site (pons vs basal forebrain vs pons and forebrain; $F=2.042 ; \mathrm{df}=2,93 ; p=0.136$ ) or drug (carbachol vs saline; $F=3.471 ; \mathrm{df}=1.93 ; p=0.066$ ) main effect on $\mathrm{W}$ duration. $B$, S sleep. ANOVA showed no significant site $(F=2.375 ; \mathrm{df}=2,93$; $p=0.099$ ) main effect on $\mathrm{S}$ sleep duration. There was a significant drug ( $F=10.596 ; \mathrm{df}=1,93 ; p=0.002)$ main effect on the duration of the longest S sleep episode. $C$, D sleep and DCarb. ANOVA demonstrated significant site $(F=26.193 ; \mathrm{df}=2,93 ; p<0.000)$ and $\operatorname{drug}(F=33.805$; df $-1,93 ; p<0.000$ ) main effects on D sleep or DCarb duration.

jection of carbachol significantly reduced DCarb latency below control levels (Fig. 6B, right histograms; $t=4.68$; $\mathrm{df}=24 ; p<$ 0.000).

Effects of basal forebrain carbachol on the frequency of behavioral state episodes. The effects of carbachol microinjection into the pons, the basal forebrain, and simultaneously into the pons and basal forebrain on the frequency with which behavioral states occurred are shown in Figure 7. Statistically significant site and drug main effects on the frequency of S sleep (Fig. $7 \mathrm{~B}$ ) and D sleep or DCarb (Fig. $7 C$ ) episodes, and significant drug main effects on $\mathrm{W}$ frequency (Fig. $7 A$ ) were revealed by ANOVA (see Fig. 7 caption for $F$ values and probability levels).

The frequency of wakefulness was significantly reduced below control levels following microinjection of carbachol into the basal forebrain (Fig. 7A, middle histograms; $t=2.30$; df $=50$; $p=0.025$ ) and simultaneously into the pons and basal forebrain (Fig. 7A, right histograms; $t=3.70 ; \mathrm{df}=24 ; p=0.001$ ). The frequency of S sleep episodes (Fig. $7 B$ ) was significantly reduced below saline control levels by microinjecting carbachol into the pons (Fig. $7 B$, left histograms; Table 1), the basal forebrain (Fig. $7 B$, middle histograms; $t=2.43$; $\mathrm{df}=50 ; p=0.019$ ), or simultaneously into the pons and basal forebrain (Fig. $7 B$, right histograms; $t=6.42$; df $=24 ; p<0.000$ ).

The frequency of D sleep or DCarb episodes (Fig. 7C) was significantly increased following pontine carbachol injections (Fig. 7C, left histograms; Table 1 ) and after simultaneous pontine and basal forebrain administration of carbachol (Fig. $7 \mathrm{C}$, right histograms; $t=3.91 ; \mathrm{df}=24 ; p=0.001$ ). As was observed for DCarb percentage (Fig. $5 C$ ), DCarb frequency per hour following pontine carbachol was significantly greater than DCarb frequency following simultaneous pontine and basal forebrain carbachol (Fig. 7C, solid histograms, left vs right, 5.6 vs 2.4 DCarb episodes, respectively; $t=2.77 ; \mathrm{df}=21 ; p=0.011$ ). Thus, simultaneous administration of carbachol into the basal forebrain reduced the ability of pontine carbachol to increase DCarb frequency (see also Fig. 4, bottom left).

Effects of basal forebrain carbachol on the duration of behavioral state episodes. The final measure of behavioral state regulation examined in this study was duration of the longest episode of W, S, and D sleep or DCarb (Fig. 8). ANOVA revealed a statistically significant drug main effect on duration of the longest $S$ sleep episode and significant site and drug main effects on duration of the longest episode for D sleep or DCarb (see Fig. 8 caption for $F$ values and probability levels).

The solid histograms of Figure $8 A$ compare $W$ duration following carbachol injection into the pons, the basal forebrain, and simultaneously into the pons and basal forebrain. ANOVA of this comparison revealed a significant site main effect of carbachol on the duration of wakefulness $(F=4.265 ; \mathrm{df}=2,46$; $p=0.020$ ). Injection site comparisons showed a significant reduction in $\mathrm{W}$ duration following pontine carbachol compared to $\mathrm{W}$ duration following basal forebrain carbachol alone (Fig. $8 A$, solid histograms, left vs middle; $t=2.77$; df $=34 ; p=$ 0.009 ). W duration following microinjection of carbachol into the pons was also less than observed following simultaneous pontine and basal forebrain carbachol (Fig. $8 A$, solid histograms, left vs right; $t=2.65 ; \mathrm{df}=21 ; p=0.015$ ). Thus, basal forebrain administration of carbachol blocked the pontine carbachol-induced decrease in $W$ duration.

$\mathrm{S}$ sleep duration was significantly reduced below control levels by microinjection of carbachol into the pons (Fig. $8 \mathrm{~B}$, left histograms; Table 1) and simultaneously into the pons and basal forebrain (Fig. $8 B$, right histograms; $t=2.93$; df $=24 ; p=$ $0.007)$. These findings are consistent with the carbachol-induced reductions in S sleep percentage (Fig. $5 B$ ) and S sleep frequency (Fig. $7 B$ ), and the carbachol-induced increase in $\mathrm{S}$ sleep latency (Fig. 6A). 
Table 2. State-independent polygraphic sleep signs

\begin{tabular}{lccll}
$\begin{array}{l}\text { Injection } \\
\text { site }\end{array}$ & $\begin{array}{l}\text { W \& } \\
\text { PGOs }\end{array}$ & $\begin{array}{l}\text { W \& } \\
\text { atonia }\end{array}$ & $\begin{array}{l}\text { W \& } \\
\text { spindles }\end{array}$ & $\begin{array}{l}\text { D \& } \\
\text { spindles }\end{array}$ \\
\hline Pons & 80 & 50 & 0 & 10 \\
Basal forebrain & 4 & 0 & 0 & 0 \\
Pons and forebrain & 69 & 38 & 0 & 0 \\
\hline
\end{tabular}

Data are the occurrence of state-independent polygraphic sleep signs during the first hour following microinjection of carbachol $(4 \mu \mathrm{g} / 0.25 \mu \mathrm{l})$. The four columns show different state-independent sleep signs, and the values represent the percentage of trials during which the state-independent sleep signs occurred. These data were tabulated using the following criteria. If five or more PGO waves occurred during a $30 \mathrm{sec}$ bin of wakefulness, then that bin was scored for the presence of W \& PGOs. If motor atonia was present for more than half of a $30 \mathrm{sec}$ bin of wakefulness, then that bin was scored for the presence of $W$ \& atonia. To be scored for the presence of W \& spindles or D \& spindles, more than half of a $30 \mathrm{sec}$ bin of $W$ or of $D$ sleep was characterized by the presence of spindles in the EEG. Transition periods from $W$ to $S$ sleep or from $S$ sleep to $D$ sleep were not included. Only one occurrence of one state-independent sign (W \& atonia) occurred following microinjection of saline $(0.25 \mu \mathrm{l})$. These analyses are based on 99 microinjection trials into 18 sites in 6 cats.

D sleep duration (Fig. 8C) was also significantly altered following carbachol injections. Simultaneous pontine and basal forebrain microinjection of carbachol produced a $448 \%$ increase in duration of the longest DCarb episode as compared with control (Fig. 8C, right histograms; $t=3.73$; $\mathrm{df}=24 ; p=0.001$ ). As was observed for DCarb percentage (Fig. $5 C$ ) and DCarb frequency (Fig. 7C), DCarb duration following pontine carbachol (Fig. 8C) was significantly greater than DCarb duration following simultaneous pontine and basal forebrain carbachol (Fig. $8 C$, solid histograms, left vs right, $38.4 \mathrm{~min}$ vs $21.3 \mathrm{~min}$, respectively; $t=2.19 ; \mathrm{d} f=21 ; p=0.040$ ). Thus, the ability of pontine carbachol to increase the duration of the longest DCarb episode was reduced by microinjection of carbachol into the basal forebrain (see also Fig. 4, bottom right).

State-independent polygraphic signs. The DCarb state is characterized by the simultaneous occurrence of muscle atonia, rapid eye movements, EEG desynchrony, PGO waves, and the behavioral appearance of sleep. Previous studies have reported that in addition to producing all of the foregoing D sleep signs, pontine carbachol administration can also elicit the occurrence of these polygraphic D sleep signs independently, without evoking a change in behavioral state from $\mathrm{W}$ to DCarb (Baghdoyan et al., 1982). For example, following microinjection of carbachol, a behaviorally awake animal can exhibit $\mathrm{PGO}$ waves (Vivaldi et al., 1980), nystagmus-like eye movements, or atonia (Baghdoyan et al., 1982), depending upon the intrapontine site of drug administration (Hobson et al., 1986). Occasional clusters of spindles in the EEG also have been observed during DCarb $(\mathrm{H}$. A. Baghdoyan, unpublished observation). Other dissociations of D sleep signs from the DCarb state following pontine carbachol administration have been described by Vanni-Mercier et al. (1989).

In order to assess the possible occurrence of state-independent sleep signs and the effects of basal forebrain injections on pontine-elicited state-independent sleep signs, the state-independent occurrence of PGO waves, skeletal muscle atonia, and EEG spindles was documented during the first $60 \mathrm{~min}$ postinjection. The results of these analyses are summarized in Table 2 . Following pontine injection of carbachol, the most frequent stateindependent sleep sign was PGO waves during behavioral and EEG wakefulness. The second most frequent state-independent sign to occur following pontine carbachol was skeletal muscle atonia during wakefulness. Table 2 also shows that basal forebrain administration of carbachol did not elicit state-independent sleep signs. Finally, following simultaneous pontine and basal forebrain administration of carbachol, the percentage of trials in which state-independent sleep signs occurred was always lower than the percentage of trials exhibiting state-independent signs following administration of carbachol into the pons alone.

Behaviors during wakefulness. The foregoing analyses show that simultaneous pontine and basal forebrain carbachol administration reduced the ability of pontine carbachol to evoke polygraphic signs of $D$ sleep, as well as the D sleep-like state. Could basal forebrain carbachol have suppressed DCarb by evoking behaviors that interfere with sleep? Table 3 documents the occurrence of several behaviors observed during the first 30 min postinjection. Following microinjection of saline, the most commonly observed behaviors were feeding and drinking. Carbachol, independent of its site of injection, reduced the percentage of trials in which feeding and drinking occurred. Circling, which rarely was observed following saline injection, occurred most frequently following pontine carbachol injection and least frequently following basal forebrain administration of carbachol. Table 3 indicates that the D sleep inhibition caused by basal forebrain carbachol administration was not due to the evocation of behaviors that indirectly suppressed sleep.

Effects of carbachol injections into the caudate nucleus. The present study is the first to assess the influence of cholinoceptive basal forebrain sites on DCarb. In order to test for anatonical specificity of the basal forebrain effect, two animals were implanted with guide tubes aimed for the caudate nucleus (Fig. $2 B$ ), a forebrain region not implicated to be directly involved in sleep cycle control. Similar to basal forebrain injections of carbachol, caudate administration of carbachol also increased wakefulness and decreased sleep. Microinjection of carbachol into the caudate nucleus ( $N=11$ trials) caused a $33 \%$ increase in the percentage of time spent awake, a $51 \%$ decrease in S sleep,

Table 3. Behaviors during wakefulness

\begin{tabular}{|c|c|c|c|c|c|c|c|c|}
\hline \multirow[b]{2}{*}{ Injection site } & \multicolumn{2}{|c|}{ Circling } & \multicolumn{2}{|c|}{ Drinking } & \multicolumn{2}{|c|}{ Feeding } & \multicolumn{2}{|c|}{ Growling } \\
\hline & $\mathrm{C}$ & $\mathrm{S}$ & $\bar{C}$ & $S$ & $\mathrm{C}$ & $\mathrm{S}$ & $\mathrm{C}$ & $S$ \\
\hline Pons & 50 & 0 & 10 & 36 & 30 & 55 & 0 & 0 \\
\hline Basal forebrain & 31 & 4 & 15 & 23 & 27 & 54 & 4 & 0 \\
\hline Pons and forebrain & 46 & 8 & 8 & 15 & 8 & 38 & 0 & 0 \\
\hline
\end{tabular}

Data are the occurrence of various wakefulness behaviors during the first $30 \mathrm{~min}$ following microinjection of carbachol $(C ; 4 \mu \mathrm{g} / 0.25 \mu \mathrm{l} ; N=49$ trials into 17 sites in 6 cats) or saline (S; $0.25 \mu \mathrm{l} ; N=50$ trials into 18 sites in 6 cats). Values represent the percentage of trials in which the behaviors occurred at least once. Animals were free to move about the recording cage ( 2 feet wide $\times 3$ feet long $\times 2$ feet high) and had unlimited access to dry food and water. 
Table 4. Comparison of pontine injection sites most effective for producing the REM sleep-like state

\begin{tabular}{|c|c|c|c|c|c|c|}
\hline \multirow[b]{2}{*}{$\underline{\text { Study }}$} & \multicolumn{3}{|c|}{$\begin{array}{l}\text { Stereotaxic coordinants of the } \\
\text { most effective injection sites }\end{array}$} & \multirow{2}{*}{$\begin{array}{l}\text { Dose } \\
(\mu \mathrm{g})\end{array}$} & \multirow{2}{*}{$\begin{array}{l}\text { Volume } \\
(\mu \mathrm{l})\end{array}$} & \multirow{2}{*}{$\begin{array}{l}\text { DCarb } \\
\text { latency } \\
\text { (min) }\end{array}$} \\
\hline & $\mathrm{P}$ & $\mathbf{L}$ & $\mathrm{V}$ & & & \\
\hline Present data & $1.9 \pm 0.9$ & $1.1 \pm 0.4$ & $-6.9 \pm 1.4$ & 4 & 0.25 & $11.0 \pm 5.9$ \\
\hline Baghdoyan et al. $(1987)^{a}$ & $2.5 \pm 0.8$ & $1.1 \pm 0.2$ & $-7.1 \pm 1.4$ & 4 & 0.25 to 0.5 & $10.3 \pm 4.6$ \\
\hline Vanni-Mercier et al. (1989)" & 2 to 3.5 & 1.8 to 2.5 & -3 & 0.4 & 0.2 & $5.5 \pm 2.7$ \\
\hline Yamamoto et al. $(1990)^{c}$ & 1 to 3.5 & 2 & -3.5 to -5.5 & 4 & 0.25 & $3.3 \pm 1.1$ \\
\hline Reinoso-Suarez et al. $(1990)^{d}$ & 2 & 2 & -5 & 0.8 to 1.2 & 0.02 to 0.03 & 5 \\
\hline
\end{tabular}

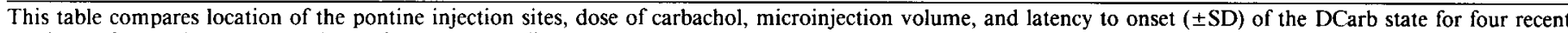

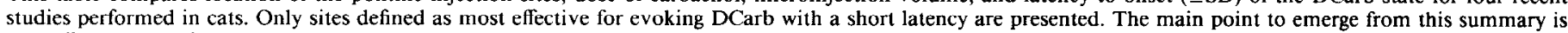

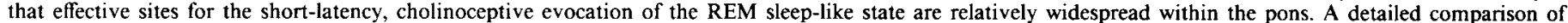
methodological differences between these five studies is provided below.

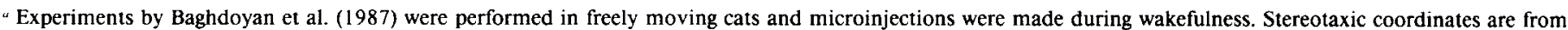

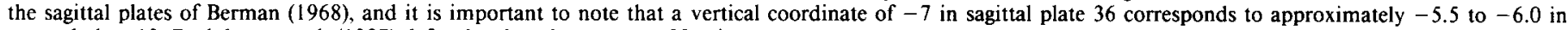
coronal plate 19. Baghdoyan et al. (1987) defined a short latency as $\leq 20 \mathrm{~min}$.

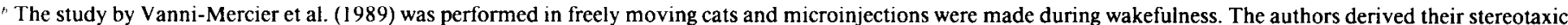
coordinates of the injection sites from sagittal brain stem sections. Vanni-Mercier et al. (1989) defined a short latency as $\leq 10$ min.

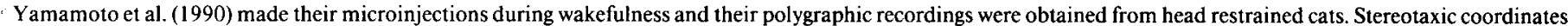
are based on the atlas of Berman (1968) and were determined from coronal sections. Yamamoto et al. (1990) defined a short latency as <5 min.

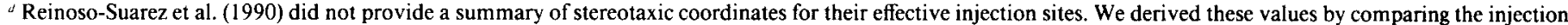

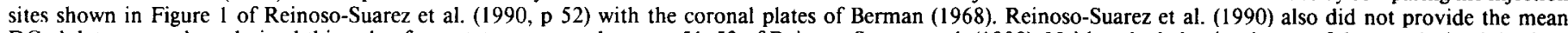

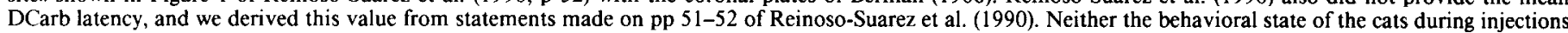
nor the restraint conditions during the recordings were reported by Reinoso-Suarez et al. (1990).

and an $81 \%$ decrease in D sleep. There were important differences, however, between the effects produced by microinjecting carbachol into the caudate and into the basal forebrain. First, $81 \%$ of carbachol injections into the caudate were followed by locomotor circling, whereas basal forebrain carbachol evoked circling in only $31 \%$ of trials (Table 3). Furthermore, $61 \%$ of the trials in which basal forebrain carbachol produced circling occurred in the same animal. In contrast, caudate carbachol administration produced circling from all four injection sites in both animals. Second, circling occurred much more frequently following simultaneous pontine and caudate carbachol administration than following simultaneous pontine and basal forebrain carbachol microinjections ( $86 \%$ vs $46 \%$ of trials, respectively). Third, $55 \%$ of caudate carbachol injections elicited hissing and growling, whereas hissing and growing occurred during only $4 \%$ (one trial) of basal forebrain carbachol injections (Table 3 ). These findings suggest that microinjection of carbachol into the caudate nucleus caused a nonspecific suppression of sleep by directly or indirectly activating motor systems.

\section{Discussion}

The results show that (1) wakefulness was enhanced following basal forebrain injection of carbachol, (2) non-REM sleep was suppressed following microinjection of carbachol into all brain sites, (3) REM sleep was increased following pontine administration of carbachol, and (4) the DCarb state was suppressed by simultaneous administration of carbachol into the basal forebrain. The results show for the first time that microinjection of carbachol into the basal forebrain significantly reduced the ability of pontine carbachol to produce a REM sleep-like state (Fig. 4). These results are discussed below with regard to the hypothesis that basal forebrain administration of carbachol activates an arousal-generating system that can successfully compete with the powerful cholinergic REM sleep-generating system of the pons.

The carbachol-evoked REM sleep-like state. The present results are consistent with previous investigations showing that pontine administration of carbachol significantly enhanced the
REM sleep-like state (reviewed in Steriade and McCarley, 1990; Velazquez-Moctezuma et al., 1990). Cholinoceptive evocation of the REM sleep-like state has been shown to be site dependent within the pons (Baghdoyan et al., 1987; Vanni-Mercier et al., 1989; Yamamoto et al., 1990), and there is presently great interest in identifying effective pontine sites for the cholinoceptive induction of the REM sleep-like state. The following discussion compares results obtained from four recent studies designed to test the hypothesis that there is anatomical site specificity within the pons for producing the REM sleep-like state with carbachol. Examination of these data (Table 4) reveals that (1) effective sites for the short-latency evocation of the REM sleep-like state are relatively widespread within the pons, (2) within a restricted pontine region there is a high degree of variability in the latency to onset of the carbachol-induced REM sleep-like state, and (3) the optimal region for short-latency evocation of the REM sleeplike state is in the anterodorsal pons.

The first systematic, quantitative study mapping the ability of pontine carbachol to evoke a REM sleep-like state used multiple-regression analyses to demonstrate a statistically significant relationship between the three-dimensional coordinates ( $\mathrm{P}, \mathrm{L}$, and $\mathrm{V}$ dimensions) of the pontine injection site and the percentage, latency, and duration of the carbachol-evoked REM sleep-like state (Baghdoyan et al., 1987). The region mapped in this previous study extended from P1.8 to P7.2, L0.3 to L1.9, and $\mathrm{V}-5.5$ to $\mathrm{V}-10$ (coordinates according to the sagittal plates of Berman, 1968). These data showed that anterodorsal pontine sites were significantly more effective than posteroventral pontine sites for the cholinoceptive evocation of the REM sleeplike state. The multiple-regression analyses also identified a region in the pontine reticular formation, rostral to the abducens nucleus and just below the ventral tegmental nucleus of Gudden, from which the REM sleep-like state could be evoked with a short latency and high percentage. From the multiple-regression equations, it was predicted that the optimal region for the cholinoceptive evocation of the REM sleep-like state would be more rostral and more dorsal than any sites previously injected (Baghdoyan et al., 1984c). 
Vanni-Mercier et al. (1989) conducted an extensive mapping study that included injection sites in the dorsal pons (Table 4). Thesc investigators evoked the REM sleep-like state from a region similar to the pontine area described above (Baghdoyan et al., 1987). In addition, shorter latency sites for induction of the REM sleep-like state were found to be located more dorsally, in the locus coeruleus alpha (LC- $\alpha$ ), the peri-LC- $\alpha$, and the immediately adjacent mediodorsal pontine tegmentum (VanniMercier et al., 1989). Thus, the empirical data of Vanni-Mercier et al. (1989) confirmed the mathematical prediction of Baghdoyan et al. (1984c, 1987) that the anterodorsal pons would be an effective region for the short-latency evocation of the REM sleep-like state, and delineated the location of this effective region (Table 4). Vanni-Mercier et al. (1989) also reported that carbachol had no effect on REM sleep latency when injected into the nearby LC, and that carbachol significantly suppressed REM sleep when injected into the PPT.

Most recently, Yamamoto et al. (1990) systematically explored the anterodorsal pontine tegmentum to examine the ability of carbachol to evoke a REM sleep-like state. Yamamoto et al. (1990) mapped an area more rostral and dorsal to the region studied by Baghdoyan et al. (1987), including part of the region studied by Vanni-Mercier et al. (1989). Yamamoto et al. (1990) found their most effective region to overlap with the most effective region of Vanni-Mercier et al. (1989) in the rostrodorsal and mediolateral planes (Tablc 4). The major difference between the findings of these two groups is that the effective region defined by Vanni-Mercier et al. (1989) is slightly more dorsal to the region defined by Yamamoto et al. (1990). A maximally effective zone for the cholinoceptive evocation of the REM sleep-like state was depicted by Yamamoto et al. (1990) as a cylinder with an axis running paramedially. Yamamoto et al. (1990) suggested that DCarb latency decreased as a function of increased distance, in any direction, between the axis of the cylinder and location of the carbachol injection site. Thus, the effective zone for producing the REM sleep-like state was proposed to be surrounded by brain areas into which microinjection of carbachol either had no effect on REM sleep or caused REM sleep suppression.

Reinoso-Suarez et al. (1990) also evaluated the effects on REM sleep of injecting carbachol into different pontine sites. They concluded that carbachol was more effective in evoking the REM sleep-like state from ventral rather than from dorsal sites. In fact, these investigators reported REM sleep suppression following carbachol injections into dorsal pontine sites. The apparent contradiction between the results obtained by Reinoso-Suarez et al. (1990) and the data described in detail above (Baghdoyan et al., 1987; Vanni-Mercier et al., 1989; Yamamoto et al., 1990) can be resulved by looking more closely at the actual location of the Reinoso-Suarez et al. (1990) injection sites rather than relying upon the descriptors "dorsal" and "ventral." As shown in Figure 1 of Reinoso-Suarez et al. (1990), at least one of their dorsal (i.e., REM sleep-suppressing) sites may have been in the PPT, an area shown by Vanni-Mercier et al. (1989) to suppress REM sleep when injected with carbachol. Yamamoto et al. (1990) also reported that carbachol injected into sites located more rostrally than P1, more laterally than L2, and more dorsally than $\mathrm{V}-3.5$ produced the longest latencies to onset and the lowest percentages of the REM sleep-like state. It appears that the dorsal injections of Reinoso-Suarez et al. (1990) were made into sites that have recently been shown to suppress REM sleep when injected with carbachol. Regarding the ventral sites of Reinoso-Suarez et al. (1990), Table 4 shows that these effective sites appear to overlap with the same region defined by Yamamoto et al. (1990) as effective in eliciting the REM sleeplike state. Thus, the results of Reinoso-Suarez et al. (1990) agree with those reported by Vanni-Mercier et al. (1989) and Yamamoto et al. (1990).

The four previous microinjection studies are summarized by Table 4. The injection sites of Baghdoyan et al. (1987) were the most ventral and the most medial within the cholinoceptive pontine reticular formation. Yamamoto ct al. (1990) used the same dose and volume as Baghdoyan et al. (1987) and obtained shorter latencies from injection sites located more dorsally and more laterally. Vanni-Mercier et al. (1989), using a 10-fold lower dose of carbachol, injected sites similar to those injected by Yamamoto et al. (1990) and obtained latencies similar to Yamamoto et al. (1990). This finding is in agreement with the dose-response curve of Baghdoyan et al. (1989), which showed that similar DCarb latencies were evoked from the same injection sites using $0.4,1.0$, and $4.0 \mu \mathrm{g}$ of carbachol. Thus, there is agreement between the three systematic mapping studies (Baghdoyan et al., 1984c, 1987; Vanni-Mercier et al., 1989; Yamamoto et al., 1990). These three studies suggest that, in contrast to the posteroventral pons, the anterodorsal pontine reticular formation is the most effective region for cholinoceptive evocation of the REM sleep-like state.

It is interesting to note that Yamamoto et al. (1990) found no significant relationship between latency to onset of the REM sleep-like state and the anatomical coordinates of the carbachol injection site. This lack of statistical significance does not mean that there is no anatomical specificity for the cholinoceptive evocation of the REM sleep-like state. It should be clear that the ability to evoke the REM sleep-like state is characterized by a high degree of variability. As can be seen in Figure $5 \mathrm{~A}$ of Yamamoto et al. (1990), from P1 to P3.5 of the pons, $35 \%$ of injections produced DCarb latencies of $<5 \mathrm{~min}, 37 \%$ of injections produced latencies of $5-10 \mathrm{~min}$, and $28 \%$ of injections were characterized by latencies $>10 \mathrm{~min}$. This variability is not unique to the data of Yamamoto et al. (1990) and is characteristic of all studies that use pontine microinjection of carbachol to produce the REM sleep-like state. This point is illustrated by Table 4 and calculations of the coefficients of variation for DCarb latency. The coefficients of variation associated with these mapping studies were 45\% (Baghdoyan et al., 1987), 49\% (VanniMercier et al., 1989), and 33\% (Yamamoto et al., 1990).

The existence of this large variability has led Lopez-Rodriguez et al. (1992) to propose that factors other than site, dose (Baghdoyan et al., 1989), or volume (Silberman et al., 1980) of injection must influence the ability of pontine carbachol to evoke the REM sleep-like state. Yamamoto et al. (1990) also suggested that the sleep cycle phase of the animal prior to and during the microinjections may influence DCarb latency. An additional factor that has not been systematically studied, but is likely to influence latency, is whether the cat is head-restrained or freely moving throughout the injection and recording interval. Although these prior conditions and methodological factors differ between the studies summarized in Table 4 , these variables were held constant within each study. In spite of the high degree of variability (mean $=42 \%$ ), these three independent mapping studies (Baghdoyan et al., 1984c, 1987; Vanni-Mercier et al., 1989; Yamamoto et al., 1990) consistently support the conclusion that anterodorsal pontine sites produce shorter DCarb latencies than posteroventral sites. 
In the present study, the purpose of the pontine carbachol injections was not to map effective sites for REM sleep generation, but rather to evoke reliably a high percentage of the REM sleep-like state with a relatively short latency. This design was used to test the hypothesis that basal forebrain carbachol administration would alter the carbachol-induced REM sleep-like state. As shown in Figure $2 A$, the pontine injection sites of the present study (mean $\pm \mathrm{SD}, \mathrm{Pl} .9 \pm 0.9, \mathrm{Ll} .1 \pm 0.4, \mathrm{~V}-6.9 \pm$ 1.4) were located in the same area that was previously defined as effective (Baghdoyan et al., 1987). The data in Table 1 confirm that carbachol injected into these sites produced a high percentage of the REM sleep-like state with a short latency to onset.

Pontine cholinergic regulation of REM sleep. Further evidence in support of the hypothesis that pontine cholinergic systems play a key role in the generation of natural REM sleep comes from the finding that a REM sleep-like state can be produced by pontinc microinjection of the $\mathrm{AChE}$ inhibitor ncostigmine (Baghdoyan et al., 1984a). In addition, we have recently reported that the release of endogenous $\mathrm{ACh}$ in the mPRF is significantly increased during the carbachol-evoked REM sleep-like state (Lydic et al., 1991). Endogenous ACh has also been measured during natural REM sleep in a nearby pontine reticular area, the dorsolateral tegmental field, and $\mathrm{ACh}$ release was significantly greater during REM sleep than during non-REM sleep or during wakefulness (Kodama et al., 1990). ACh measured in the mPRF is presumed to be released from neurons whose cell bodies lie in the dorsolateral pons. Anatomical studies (Mitani et al., 1988; Shiromani et al., 1988) have shown that cholinergic neurons of the LDT and PPT send projections to the cholinoceptive region of the $\mathrm{mPRF}$ from which a REM sleep-like state can be evoked pharmacologically, and electrical stimulation of the PPT causes increased ACh release in the MPRF (Lydic and Baghdoyan, 1992). Finally, selective lesions of the dorsolateral pontine cholinergic nuclei disrupt REM sleep (Webster and Jones, 1988; Shouse and Siegel, 1992), and single-unit recording studies across the sleep-wake cycle have revealed a population of putatively cholinergic neurons located in the LDT and PPT that increase their discharge rates prior to and during natural REM sleep (El Mansari et al., 1989; Steriade et al., 1990; Kayama et al., 1992). Taken together, these data strongly support the hypothesis that cholinergic neurons of the dorsolateral pons and non-cholinergic, cholinoceptive neurons of the $m P R F$ are critically involved in the generation of REM sleep.

The mechanisms by which cholinergic and non-cholinergic, cholinoceptive pontine neurons interact with other brain regions and other neurotransmitter systems to produce the state of REM sleep are the focus of current investigation (for review, see Steriade and McCarley, 1990). Although it has been known since the early brain transection studies of Jouvet (1962) that the pons can produce REM sleep without input from the telencephalon, diencephalon, or midbrain, it is clear that forebrain systems influence the activity of the pontine REM sleep generator (Mancia and Marini, 1990). The present data, summarized by Figure 4 , show that basal forebrain carbachol administration reduced the ability of pontine carbachol to evoke the REM sleep-like state. The present data thus raise the question of what pathways and mechanisms might basal forebrain inhibition of REM sleep be mediated.

Basal forebrain inhibition of REM sleep: possible neuroanatomical substrates. Direct projections from the basal forebrain to the rostral pontine reticular formation, including the LDT and PPT, have been described in several species (for reviews, see Koliatsos et al., 1990; Steriade and McCarley, 1990). Parent et al. (1988) studied forebrain projections to the PPT in the cat using retrograde transport techniques and found that the most heavily labeled forebrain neurons following injection of tracer into the PPT were located in the medial and lateral part of the bed nucleus of the stria terminalis and the nucleus of the anterior commissure. Labeling was also observed in the preoptic area, the substantia innominata, the ventral pallidum, and the ventrolateral part of the horizontal limb of the diagonal band of Broca, indicating that these areas also project to the PPT. As shown in Figure $2 A$, some of the present injection sites were in forebrain areas known to project to LDT and PPT. If carbachol injection into these basal forebrain sites activated, either directly or indirectly, a projection system that inhibited LDT and PPT, then such inhibition might comprise one mechanism by which basal forebrain carbachol reduced both natural REM sleep and the carbachol-induccd REM sleep-like state. Given that basal forebrain cholinergic neurons are hyperpolarized by muscarine (Khateb et al., 1991), and that few of the basal forebrain projections to the PPT are cholinergic (Parent et al., 1988; Koliatsos et al., 1990), it is unlikely that cholinergic neurons mediated the REM sleep-suppressive effects of basal forebrain carbachol reported here.

Basul forebrain control of non-REM sleep. Several lines of evidence suggest that the basal forebrain may play a role in the active generation of non-REM sleep (reviewed in Szymuziak and McGinty, 1990). The present results, however, showed that basal forebrain administration of carbachol suppressed nonREM sleep (Figs. 5-8). These data suggest that sleep-active basal forebrain neurons (Szymusiak and McGinty, 1986) are not cholinoceptive or that this population of basal forebrain neurons may be inhibited by carbachol.

Hernandez-Peon et al. (1963, 1967) evoked slecp following forebrain administration of $\mathrm{ACh}$. Most of their injection sites were more lateral and more caudal than the sites microinjected with carbachol in the present study (Fig. 2A). Methodological differences between the present study and the studies of Hernandez-Peon et al. $(1963,1967)$ (microinjection of known dosages vs application of ACh crystals, respectively) and the manipulation of different forebrain areas are likely to account for the different findings from these two laboratories.

Basal forebrain enhancement of wakefulness. The present results show that microinjection of carbachol into the basal forebrain produced an increase in wakefulness. The mechanisms by which this effect was mediated are not known. It has been suggested that cholinergic neurons of the basal forebrain produce neocortical activation and behavioral arousal by a dual mechanism involving direct projections to the cortex and suppression of reticular thalamic neurons responsible for spindle generation (Buzsaki et al., 1988; Steriade and Buzsaki, 1990). ACh acting via a muscarinic receptor mechanism has been shown to inhibit cholinergic basal forebrain neurons in vitro (Khateb et al., 1991), and basal forebrain carbachol administration in rats reduced ACh turnover in the cortex (Robinson et al., 1988), suggesting that carbachol inhibits basal forebrain cholinergic neurons in vivo. If this is also true in the cat, then it is unlikely that basal forebrain carbachol administration in the present study could have increased wakefulness by activating cholinergic projection neurons.

Limitations and conclusions. The present results point to the need to specify the cellular level mechanisms by which cholinoceptive, basal forebrain neurons influence pontine REM sleep 
generating systems. While it has been shown that carbachol depolarizes the majority of non-cholinergic mPRF neurons (Greene et al., 1989), it appears that carbachol inhibits both pontine (Leonard and Llinas, 1988, 1990) and basal forebrain (Khateb et al., 1991) cholinergic neurons. The present data cannot address the cellular-level mechanism by which basal forebrain administration of carbachol produced its effects on sleep and wakefulness.

Another limitation, which can be addressed by future studies, concerns the incomplete understanding of the types of cholinergic receptors in the basal forebrain. Whereas evocation of the carbachol-induced REM sleep like state from the pons has been shown to be dose dependent and mediated by muscarinic, cholinergic receptors (Hobson et al., 1983; Baghdoyan et al., 1984a, 1989; Velazquez-Moctezuma et al., 1989, 1991), the cholinergic receptor type in the basal forebrain mediating the increased wakefulness of the present report remains to be elucidated.

The anatomical extent of cholinoceptive basal forebrain sites that increase wakefulness and suppress sleep also remains to be determined. The present results encourage more extensive mapping studies designed to demarcate the site specificity of the basal forebrain carbachol effects on sleep and wakefulness.

In spite of the above limitations, the present results show for the first time that cholinoceptive regions of the basal forebrain can suppress the occurrence of natural REM sleep and reduce the ability of pontine carbachol to evoke the REM sleep-like state. These findings encourage future studies aiming to specify the cellular and receptor level mechanisms by which the basal forebrain can influence pontine REM sleep-generating systems.

\section{References}

Baghdoyan HA (1991) Cholinergic REM sleep generation: the carbachol model. Sleep Res 20A:20.

Baghdoyan HA, Rodrigo-Angulo ML, McCarley RW, Hobson JA (1982) Cholinergic induction of desynchronized sleep by carbachol microinjection shows intrapontine site differentiation. Sleep Res 11:52.

Baghdoyan HA, Monaco AP, Rodrigo-Angulo ML, Assens F, McCarley RW, Hobson JA (1984a) Microinjection of neostigmine into the pontine reticular formation of cats enhances desynchronized sleep signs. J Pharmacol Exp Ther 231:173-180.

Baghdoyan HA, Rodrigo-Angulo ML, McCarley RW, Hobson JA (1984b) Site-specific enhancement and suppression of desynchronized sleep signs following cholinergic stimulation of three brainstem regions. Brain Res 306:39-52.

Baghdoyan HA, McCarley RW, Hobson JA (1984c) Is there an optimal site for desynchronized sleep generation by cholinergic microstimulation of the pons? Sleep Res 13:40.

Baghdoyan HA, Rodrigo-Angulo ML, McCarley RW, Hobson JA (1987) A neuroanatomical gradient in the pontine tegmentum for the cholinoceptive induction of desynchronized sleep signs. Brain Res 414 245-261.

Baghdoyan HA, Lydic R, Callaway CW, Hobson JA (1989) The carbachol-induced enhancement of desynchronized sleep signs is dose dependent and antagonized by centrally administered atropine. Neuropsychopharmacology 2:67-79.

Baghdoyan HA, Lydic R, Rutherford TM, Snyder SG (1990) Simultaneous forebrain and pontine microinjections of carbachol suppress REM sleep. Soc Neurosci Abstr 16:98.

Berman AL (1968) The brain stem of the cat. Madison: University of Wisconsin.

Berman AL, Jones EG (1982) The thalamus and basal telencephalon of the cat. Madison: University of Wisconsin.

Buzsaki G, Bickford KG, Ponomareff G, Thai LJ, Mandel R, Gage F (1988) Nucleus basalis and thalamic control of neocortical activity in the freely moving rat. J Neurosci 8:4007-4026.

Chase MH, Morales FR (1990) The atonia and myoclonia of active (REM) sleep. Annu Rev Psychol 41:557-584.
El Mansari M, Sakai K, Jouvet M (1989) Unitary characteristics of presumptive cholinergic tegmental neurons during the sleep-waking cycle in freely moving cats. Exp Brain Res 76:519-529.

Greene RW, Haas HL, Gerber U, McCarley RW (1989) Cholinergic activation of medial pontine reticular formation neurons in vitro. In: Central cholinergic synaptic transmission (Frotscher M, Misgeld U, eds), pp 123-137. Berlin: Birkhauser.

Hernandez-Peon R, Chavez-Ibarra G, Morgane PJ, Timo-laria C (1963) Limbic cholinergic pathways involved in sleep and emotional behavior. Exp Neurol 8:93-111.

Hernandez-Peon R, O'Flaherty JJ, Mazzuchelli-O'Flaherty AL (1967) Sleep and other behavioral effects induced by acetylcholinic stimulation of basal temporal cortex and striate structures. Brain Res 4: 243-267.

Hobson JA (1990) Sleep and dreaming. J Neurosci 10:317-382.

Hobson JA, Goldberg M, Vivaldi E, Riew D (1983) Enhancement of desynchronized sleep signs after pontine microinjection of the muscarinic agonist bethanechol. Brain Res 275:127-136.

Hobson JA, Lydic RA, Baghdoyan HA (1986) Evolving concepts of sleep cycle generation: from brain centers to neuronal populations. Behav Brain Sci 9:371-448.

Imeri L, Bianchi S, Angeli P, Mancia M (1991) Differential effects of M2 and M3 muscarinic antagonists on the sleep-wake cycle. NeuroReport 2:383-385.

Jones BE (1991) Paradoxical sleep and its chemical/structural substrates in the brain. Neuroscience 40:637-656.

Jones BE, Beaudet A (1987) Retrograde labeling of neurons in the brain stem following injections of $\left[{ }^{3} \mathrm{H}\right]$ choline into the forebrain of the rat. Exp Brain Res 65:437-448.

Jouvet M (1962) Recherches sur les structures nervouses et les mecanismes responsables des differentes phases du sommeil physiologique. Arch Ital Biol 100:125-206.

Kayama Y, Ohta M, Jodo E (1992) Firing of 'possibly' cholinergic neurons in the rat laterodorsal tegmental nucleus during sleep and wakefulness. Brain Res 569:210-220.

Khateb A, Serafin M, Jones BE, Alonso A, Muhlethaler M (1991) Pharmacological study of basal forebrain neurons in guinea pig brain. Soc Neurosci Abstr 17:881.

Kodama T, Takahashi Y, Honda Y (1990) Enhancement of acetylcholine release during paradoxical sleep in the dorsal tcgmental ficld of the cat brain stem. Neurosci Lett 114:277-282.

Koliatsos VE, Martin LJ, Price DL (1990) Efferent organization of the mammalian basal forebrain. In: Brain cholinergic systems (Steriade M, Biesold D, eds), pp 120-152. New York: Oxford UP.

Leonard CS, Llinas R (1988) Electrophysiology of thalamic-projecting cholinergic brainstem neurons and their inhibition by ACh. Soc Neurosci Abstr 14:297.

Leonard CS, Llinas R (1990) Electrophysiology of mammalian pedunculopontine and laterodorsal tegmental neurons: implications for the control of REM sleep. In: Brain cholinergic systems (Steriade M, Biesold D, eds), pp 205-223. New York: Oxford UP.

Lopez-Rodriguez F, Morales FR, Chase, MH (1992) Induction of muscle atonia by the microiontophoretic injection of cholinergic drugs into the brainstem reticular formation. Sleep Res 21:8.

Lydic R, Baghdoyan HA (1993) The neurobiology of REM sleep. In: Sleep and breathing, 2d ed (Saunders NA, Sullivan C, eds), in press. New York: Dekker.

Lydic R, Baghdoyan HA (1992) Cholinergic pontine mechanisms causing state-dependent respiratory depression. NIPS New Physiol Sci 7:220-224.

Lydic R, Baghdoyan HA, Zwillich CW (1989) State-dependent hypotonia in posterior cricoarytenoid muscles of the larynx caused by cholinoceptive reticular mechanisms. FASEB J 3:1625-1631.

Lydic R, Baghdoyan HA, Lorinc Z (1991) Microdialysis reveals enhanced pontine acetylcholine release during state-dependent respiratory depression. Am J Physiol 261:R766-R770.

Mancia M, Marini G, eds (1990) The diencephalon and sleep. New York: Raven.

Mitani A, Ito K, Hallanger AH, Wainer BH, Kataoka K, McCarley RW (1988) Cholinergic projections from the laterodorsal and pedunculopontine tegmental nuclei to the pontine gigantocellular tegmental field in the cat. Brain Res 451:397-402.

Nauta WJH (1946) Hypothalamic regulation of sleep in rats. An experimental study. J Neurophysiol 9:285-316.

Parent A, Pare D, Smith Y, Steriade M (1988) Basal forebrain cho- 
linergic and noncholinergic projections to the thalamus and brainstem in cats and monkeys. J Comp Neurol 277:281-301.

Reinoso-Suarez F, Rodrigo-Angulo ML, Rodriguez-Veiga E, De Andres I (1990) Thalamic connections of the oral pontine tegmentum sites whose cholinergic stimulation produces enhancement of paradoxical sleep signs. In: The diencephalon and sleep (Mancia M, Marini G, cds), pp 49-63. New York: Raven.

Robinson SE, Hambrecht KL, Lyeth BG (1988) Basal forebrain carbachol injection reduces cortical acetylcholine turnover and disrupts memory. Brain Res 445:160-164.

Sallanon M, Denoyer M, Kitahama K, Aubert C, Gray AN, Jouvet M (1989) Long-lasting insomnia induced by preoptic neuron lesions and its transient reversal by muscimol injection into the posterior hypothalamus in the cat. Neuroscience 32:669-683.

Shiromani PJ, Armstrong DM, Gillin JC (1988) Cholinergic neurons from the dorsolateral pons project to the medial pons: a WGA-HRP and choline acetyltransferase immunohistochemical study. Neurosci Lett 95:19-23.

Shouse MN, Siegel JM (1992) Pontine regulation of REM sleep components in cats: integrity of the pedunculopontine tegmentum (PPT) is important for phasic events but unnecessary for atonia during REM sleep. Brain Res 571:50-63.

Silberman EK, Vivaldi E, Garfield J, McCarley RW, Hobson JA (1980) Carbachol triggering of desynchronized sleep phenomena: enhancement via small volume infusions. Brain Res 191:215-224.

Steriade M, Buzsaki G (1990) Parallel activation of thalamic and cortical neurons by brainstem and basal forebrain cholinergic systems. In: Brain cholinergic systems (Steriade M, Biesold D, eds), pp 3-62. New York: Oxford UP.

Steriade M, McCarley RW (1990) Brainstem control of wakefulness and sleep. New York: Plenum.

Steriade M, Datta S, Oakson G, Dossi RC (1990) Neuronal activities in brainstem cholinergic nuclei related to tonic activation processes in thalamocortical systems. J Neurosci 10:2541-2559.

Swanson LW, Mogenson GJ, Gerfen CR, Robinson P (1984) Evidence for a projection from the lateral preoptic area and substantia innominata to the 'mesencephalic locomotor region' in the rat. Brain Res 295:161-178.

Swanson LW, Mogenson GJ, Simerly RB, Wu M (1987) Anatomical and electrophysiological evidence for a projection from the medial preoptic area to the 'mesencephalic and subthalamic locomotor regions' in the rat. Brain Res 405:108-122.
Szymusiak R, McGinty D (1986) Sleep-related neuronal discharge in the basal forebrain of cats. Brain Res 370:82-92.

Szymusiak R, McGinty D (1989) Sleep-waking discharge of basal forebrain projection neurons in cats. Brain Res Bull 22:423-430.

Szymusiak R, McGinty D (1990) State-dependent neurophysiology of the basal forebrain: relationship to sleep, arousal, and thermoregulatory function. In: The diencephalon and sleep (Mancia M, Marini $G$, eds), pp 111-123. New York: Raven.

Ursin R, Sterman MB (1981) A manual for standardized scoring of sleep and waking states in the adult cat. Los Angeles: Brain Information Service/Brain Research Institute, University of California.

Vanni-Mercier G, Sakai K, Lin JS, Jouvet M (1989) Mapping of cholinoceptive brainstem structures responsible for the generation of paradoxical sleep in the cat. Arch Ital Biol 127:133-164.

Velazquez-Moctezuma J, Gillin JC, Shiromani PJ (1989) Effect of specific $\mathrm{M} 1$ and M2 muscarinic receptor agonists on REM sleep generation. Brain Res 503:128-131.

Velazquez-Moctezuma J, Shiromani PJ, Gillin JC (1990) Acctylcholine and acetylcholine receptor subtypes in REM sleep generation. Prog Brain Res 84:407-413.

Velazquez-Moctezuma J, Shalauta M, Gillin JC, Shiromani PJ (1991) Cholinergic antagonists and REM sleep generation. Brain Res 543: 175-179.

Vincent SR, Reiner PB (1987) The immunohistochemical localization of choline acetyltransferase in the cat brain. Brain Res Bull 18:371415.

Vivaldi E, McCarley RW, Hobson JA (1980) Evocation of desynchronized sleep signs by chemical microstimulation of the pontine hrainstem. In: The reticular formation revisited (Hobson JA, Brazier MAB, eds), pp 513-529. New York: Raven.

von Economo C (1929) Schlaftheorie. Ergeb Physiol 28:312-339.

von Economo C (1930) Sleep as a problem of localization. J Nerv Ment Dis 71:249-259.

Webster HH, Jones BE (1988) Neurotoxic lesions of the dorsolateral pontomesencephalic tegmentum-cholinergic cell area in the cat. II. Effects upon sleep-waking states. Brain Res 458:285-302.

Yamamoto K, Mamelak AN, Quattrochi JJ, Hobson AH (1990) A cholinoceptive desynchronized sleep induction zone in the anterodorsal pontine tegmentum: locus of sensitive region. Neuroscience 39:279-293. 